\title{
Epigenetic Regulation in Plant Responses to the Environment
}

\author{
David C. Baulcombe ${ }^{1}$ and Caroline Dean ${ }^{2}$ \\ ${ }^{1}$ Department of Plant Science, University of Cambridge, Cambridge CB2 3EA, United Kingdom; ${ }^{2}$ Department of Cell \\ and Developmental Biology, John Innes Centre, Norwich NR4 7UH, United Kingdom \\ Correspondence:dcb40@cam.ac.uk
}

\section{SUMMARY}

In this article, we review environmentally mediated epigenetic regulation in plants using two case histories. One of these, vernalization, mediates adaptation of plants to different environments and it exemplifies processes that are reset in each generation. The other, virus-induced silencing, involves transgenerationally inherited epigenetic modifications. Heritable epigenetic marks may result in heritable phenotypic variation, influencing fitness, and so be subject to natural selection. However, unlike genetic inheritance, the epigenetic modifications show instability and are influenced by the environment. These two case histories are then compared with other phenomena in plant biology that are likely to represent epigenetic regulation in response to the environment.

\section{Outline}

1 Epigenetic regulation as environmental memory

2 Case history I-Vernalization

3 Case history II-Virus-induced gene silencing and epigenetics

4 Resetting versus transgenerational inheritance

5 Transient epigenetic regulation in response to stress
6 Transgenerational epigenetic regulation in response to stress

7 Epigenetic effects on genome structure

8 The heritable legacy of induced epigenetic changes

9 Perspective

References

Editors: C. David Allis, Marie-Laure Caparros, Thomas Jenuwein, and Danny Reinberg

Additional Perspectives on Epigenetics available at www.cshperspectives.org

Copyright (C 2014 Cold Spring Harbor Laboratory Press; all rights reserved; doi: 10.1101/cshperspect.a019471

Cite this article as Cold Spring Harb Perspect Biol 2014;6:a019471 


\section{OVERVIEW}

Epigenetic modification of plant genomes resembles that of mammals in that there is a similar profile of histone marks and the DNA can be methylated at cytosine residues. However, plant epigenomes are more susceptible to environmental influence than those in animals. In this article we review environmentally mediated epigenetic regulation in plants using two case histories. One of these involves a repressor of flowering, FLC. The basal level of expression of $F L C$ is set by opposing processes that either activate or repress its level of expression. The activation involves a transcriptional regulator-FRIGIDA — and the repression involves activities grouped within the so-called "autonomous pathway," which reduce $\mathrm{H} 3 \mathrm{~K} 4$ and $\mathrm{H} 3 \mathrm{~K} 36$ methylation modifications associated with active chromatin and increase H3K27 methylation, associated with silent chromatin. FLC expression is then epigenetically silenced following exposure to prolonged cold through a process known as vernalization. An early step in vernalization is the cold-induced expression of noncoding RNAs at the FLC locus. The cold exposure also leads to progressive recruitment of a plant homeodomain (PHD)-Polycomb protein $\mathrm{Su}(\mathrm{z}) 12$ (PRC2) complex to a localized region within the FLC gene. Subsequent spreading of this complex then leads to high levels of H3K27 methylation over the whole locus. The quantitative nature of vernalization is the result of cell-autonomous switching of FLC expression off in an increasing proportion of cells. Variation in this epigenetic silencing mechanism underpins the adaptation of plants to climates with different winters. The vernalization requirement is reset during gametogenesis or embryogenesis so that flowering is dependent on exposure to cold in each generation.

The second case history involves virus-induced silencing and epigenetic marks associated with methylation of DNA. The mechanism of virus-induced epigenetic modification is likely to involve a pathway that has also been implicated in transposon silencing in which Dicer generates small interfering RNAs (siRNAs) that are targeted to a chromatin-bound scaffold RNA in association with an Argonaute protein. DNA methyltransferases are then recruited to the chromatin locus where they introduce methyl groups onto $\mathrm{C}$ residues in $\mathrm{CG}, \mathrm{CHG}$, and $\mathrm{CHH}$ contexts. These DNA methylation marks may result in silencing of gene expression if they are in or close to promoter sequences and, in some instances, they are inherited across generations. If there is heritable phenotypic variation due to the gene silencing effect, there also can be an effect on fitness that is subject to natural selection. However, unlike genetic inheritance, the epigenetic modifications are unstable and are influenced by the environment.

These two case histories illustrate mechanisms that are likely to explain phenomena in plant biology in which stresses of various kinds can trigger responses that persist for longer than the inducing stimulus. In some instances, the persistence extends across generations indicating the potential role of epigenetic mechanisms in evolution. 


\section{EPIGENETIC REGULATION AS ENVIRONMENTAL MEMORY}

Plants monitor day/night and seasonal cycles to align their metabolism, growth, and development to changing environmental conditions. This plasticity requires signal perception/integration, changing gene expression in response to those signals, and then maintenance of that response until conditions change again. Epigenetic mechanisms, by definition, allow changed states to persist through cell divisions, even in the absence of the inducing stimulus, and they provide a molecular memory that underpins the maintenance phase of these responses.

Many of the environmentally induced epigenetic changes in plants are reset during gametogenesis, as are most epigenetic marks in animals. However, some persist through gametogenesis and can be stable through many generations. There is, therefore, the definite potential for transgenerational epigenetic change in plants whereas, in animals, this possibility is more controversial.

There are two factors that account for the greater potential for heritable epigenetic regulation in plants versus animals. First, there is the late differentiation of the germline. It is not laid down in embryogenesis as in animals, but it arises from somatic tissue after flowering in the male and female reproductive organs (illustrated in Fig. 1 of Pikaard and Mittelsten Scheid 2014). The plant germline cells are, therefore, descended from somatic cells and they carry epigenetic marks as persistent remnants of earlier environmental stimuli. The second factor to differentiate transgenerational inheritance in plants and animals is related to epigenetic erasure during embryogenesis, which is more complete in animals than in plants (Gutierrez-Marcos and Dickinson 2012).

The first sections of this article describe plant case histories in which induced epigenetic changes are well-understood and can be used as a general framework for further analysis of the role of the environment as a trigger for epigenetic changes. Later, in Sections 4-8 of this article, we discuss various examples in plant biology that are likely to represent epigenetic responses to environmental stimuli.

\section{CASE HISTORY I - VERNALIZATION}

Plants are sessile and they have to continually adjust their growth and physiology to changing environmental conditions. This adjustment is particularly important in developmental timing: Plants need to align their seed production to periods with favorable environmental conditions to maximize reproductive success. Environmental cues are therefore monitored and can act to regulate the timing of different developmental switches. One of the earliest characterized processes involving epigenetic regu- lation in plants is vernalization. This is the ability of plant cells to "remember" they have experienced periods of prolonged cold (measured by the number of weeks at $\sim 5^{\circ} \mathrm{C}$ ) or winter (Purvis and Gregory 1952).

This vernalization memory even persists through tissue culture. Single cells of a vernalized plant can be cultured and regenerated into new plants that flower without prolonged cold (Burn et al. 1993). Each sexual generation of plants, however, needs re-vernalizing because the vernalized state is effectively reset during meiosis or embryo formation (Fig. 1).

The biological function of vernalization is to align flowering with spring and the return of more favorable environmental conditions. This ensures effective flower formation, pollination, and fruit set. Breeding for vernalization has increased the production range of most of our major crops although the process has malign association from the Soviet era. The Soviet scientist and politician, Lysenko, claimed falsely that a vernalized state could be inherited into subsequent generations and increase wheat yields. His anti-Mendelian doctrine gained him power and influence in the political establishment and influenced practice in wheat production. However, when crops failed, it led to mass starvation and the persecution of Vavilov and other geneticists.

\subsection{Memory of Winter Involves Polycomb Silencing}

Vernalization involves the epigenetic silencing of a floral repressor in response to cold periods. In Arabidopsis, the repressor has been identified as FLOWERING LOCUS C (FLC; Michaels and Amasino 1999; Sheldon et al. 1999), a MADS box transcriptional regulator that represses genes required to switch the meristem to a floral fate. Prolonged cold progressively silences expression of FLC and this is epigenetically maintained during subsequent development in the warm (Fig. 1). Vernalization thus provides a clear example of the separation of the establishment and maintenance phases of epigenetic gene silencing.

In the absence of cold, FLC acts as a brake to flowering. The restraint is removed following prolonged cold so that, once plants have detected inductive photoperiods and warm ambient temperatures, the switch to flowering is activated. The repression of FLC is epigenetically stable and is maintained for many months after the cold exposure until embryogenesis in the next generation.

Many pathways regulate FLC and variation in their activity determines the reproductive habit of the plant. High FLC levels cause plants to overwinter before flowering, thereby limiting flowering to once a year. Low FLC levels enable plants to flower without the need for cold, opening up the possibility of reproducing more than once a year. 
D.C. Baulcombe and C. Dean

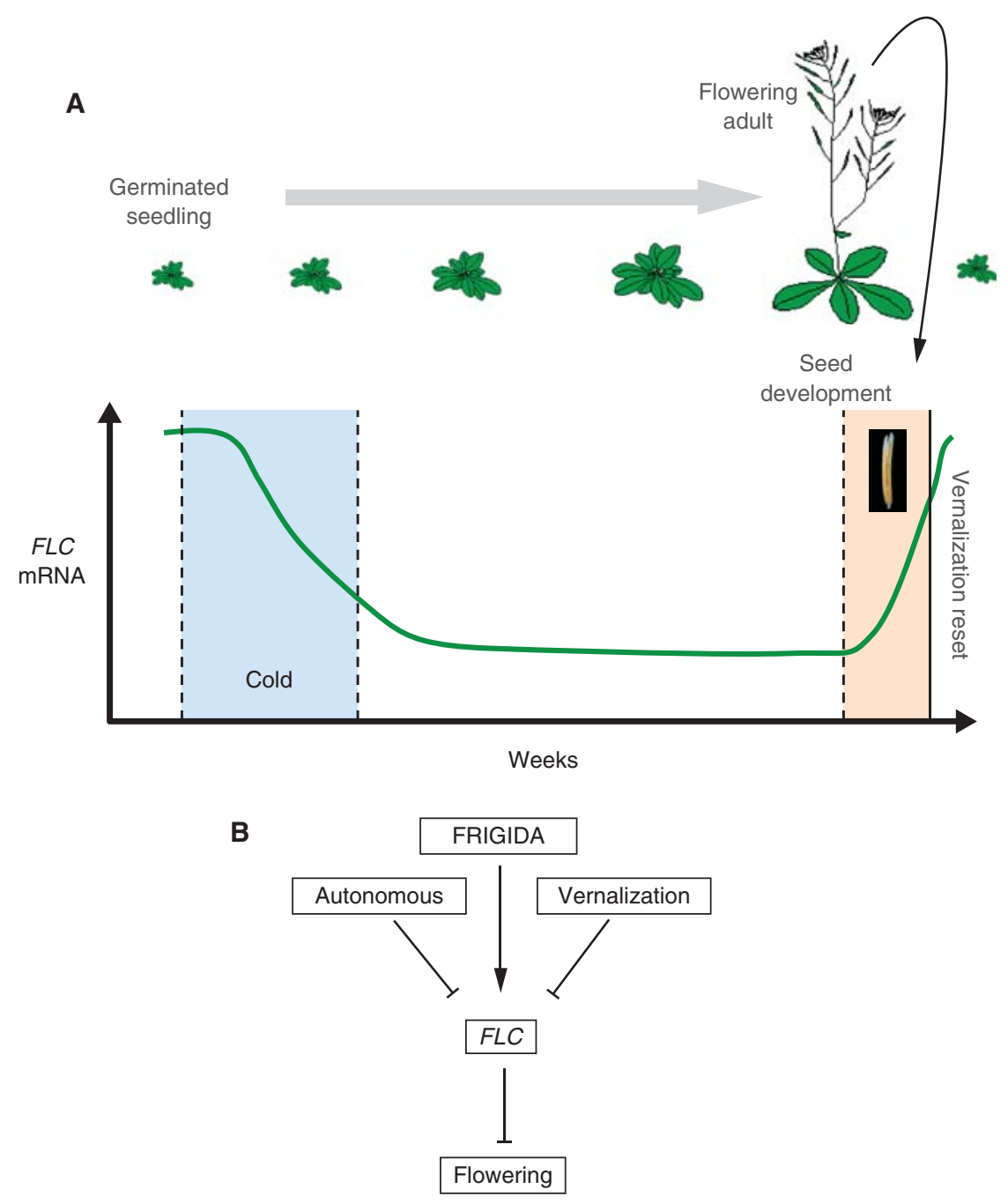

Figure 1. FLC expression is epigenetically silenced by cold and reset during embryo development. (A) The floral repressor gene, FLC, is highly expressed in young seedlings. As plants perceive cold, the expression is quantitatively repressed, dependent on the length of cold experienced. As temperatures warm in spring, the repression is epigenetically maintained until seed development when it is reset. This ensures that each generation of seedlings requires vernalization. (B) Epigenetic and transcriptional pathways activate or inhibit FLC expression and, hence, contribute to flowering time control. Chromatin modifications and noncoding RNAs contribute in different ways to each pathway.

The level of expression of FLC is set very early in development: in the early multicellular embryo for maternally derived FLC, and in the sporogenous pollen mother cells or single-celled zygote for the paternal copy (Sheldon et al. 2008; Choi et al. 2009). Many regulators determine this expression level (summarized by pathway in Fig. 1B; Crevillen and Dean 2010) and this is subject to extensive natural variation (Shindo et al. 2005).

FRIGIDA, the main activator of FLC expression (Johanson et al. 2000), is a novel protein with coiled-coil domains that directly interacts with the nuclear cap-binding complex (Geraldo et al. 2009). Its function requires the conserved RNA polymerase-associated factor 1 complex ( He et al. 2004; Oh et al. 2004; Park et al. 2010; Yu and Michaels 2010) of H3K4 methyltransferases of the Set1-class (Arabidopsis TRITHORAX-RELATED7, ATRX7) and Trithoraxclass (ATX1/2; Tamada et al. 2009); and a Set2-class methyltransferase, EARLY FLOWERING IN SHORT DAYS, (also called SET domain group 8; Xu et al. 2008). Thus, increased FLC expression is linked to trimethylation on histone $\mathrm{H} 3$ at lysine 4 (H3K4me3) and lysine 36 (H3K36me3; Xu et al. 2008; Jiang et al. 2009).

Functioning antagonistically to these activators is the autonomous pathway, which reduces $\mathrm{H} 3 \mathrm{~K} 4$ and H3K36 methylation and increases H3K27 methylation. The autonomous pathway is comprised of a series of activities linking 
RNA processing of the FLC antisense transcripts with the H3K4 demethylase FLOWERING LOCUS D (Liu et al. 2007, 2010) and Polycomb regulation involving VERNALIZATION2 (VRN2, a Su(z)12 homolog), SWINGER, or CURLY LEAF (SWN, CLF, E(z) HMTase homologs), FERTILIZATION-INDEPENDENT ENDOSPERM (an extra sex combs homolog), and MSI1 (a p55 homolog; Fig. 2) (Wood et al. 2006). The balance of these antagonistic FRIGIDA and autonomous pathways determines levels of FLC expression in the young seedlings and establishes whether or not they require vernalization for flowering (i.e., whether or not they need to overwinter before flowering).

FLC expression is progressively silenced by vernalization as plants are exposed to increasing periods of cold. This epigenetic process translates the prolonged exposure to cold into a stable silencing of FLC expression. This is maintained throughout the rest of development until it is reset in the embryo (Fig. 1). Early molecular work investigated whether the mitotic memory of vernalization involved changes in DNA methylation, a well-characterized epigenetic mark in plants (reviewed in Finnegan et al. 2000). However, there is little DNA methylation at the FLC locus and it does not change with cold (Finnegan et al. 2005). A classic mutagenesis strategy identified H3K27me3, and the Polycomb protein $\mathrm{Su}(\mathrm{z}) 12$ (PRC2) as required for the memory of FLC silencing (Gendall et al. 2001). Reminiscent of Polycomb silencing in mammalian embryonic stem cells, Arabidopsis PRC2 is already localized at FLC before silencing (De Lucia et al. 2008). This is unlike the situation in Drosophila in which PRC2 gener-
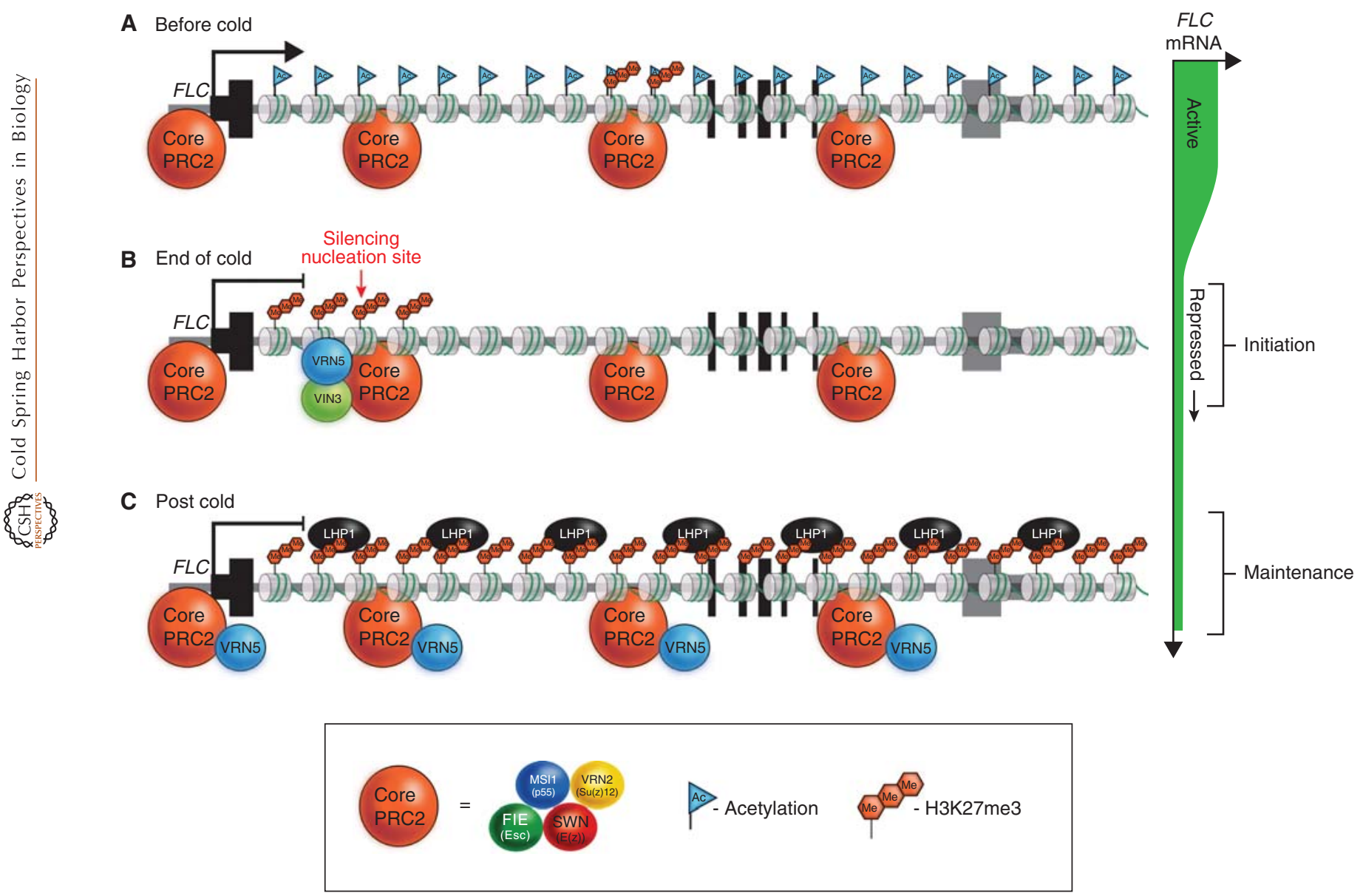

Figure 2. The Polycomb complex composition and localization changes dynamically at FLC during different phases of vernalization. (A) Before the onset of cold, which triggers vernalization, the PRC2 core complex is already associated with chromatin over the length of the active FLC locus. The exon-intron structure is indicated beneath the chromatin fiber as black bars for each exon. (B) Prolonged cold leads to the accumulation and nucleation of an alternative Polycomb complex containing plant homeodomain (PHD) proteins (VIN3, VRN5) at a specific intragenic site near the beginning of the first intron. $(C)$ In plants returned to warm conditions, the cold-induced VIN3 PHD protein is lost. A modified PHD-PRC2 complex associates across the whole locus, inducing high levels of $\mathrm{H} 3 \mathrm{~K} 27 \mathrm{me} 3$, which blanket the locus and provide repressive epigenetic stability (maintenance). 
ally associates with targets after repression of transcription by other factors ( for more detail, see Grossniklaus and Paro 2014). Two proteins, VRN5 and VIN3, containing PHD and FNIII domains then associate with PRC2 to trigger the silencing (Mylne et al. 2006; Sung et al. 2006b; Wood et al. 2006; Greb et al. 2007; De Lucia et al. 2008).

An important part of the cold-induced epigenetic silencing at FLC is the cold-induced expression of one of the PHD proteins (VIN3; Sung and Amasino 2004). VIN3 heterodimerizes with the constitutively expressed PHD protein (VRN5; Greb et al. 2007) and they associate with PRC2 at a site within the first intron of FLC, causing local accumulation of the histone modification H3K27me3, typical of Polycomb silencing (Fig. 2). On transfer of plants back to warm temperatures, a PHD-PRC2 complex then spreads along the length of $F L C$, generating very high levels of $\mathrm{H} 3 \mathrm{~K} 27 \mathrm{me} 3$ across the whole locus. These very high levels of $\mathrm{H} 3 \mathrm{~K} 27 \mathrm{me} 3$ are required for the epigenetic maintenance of the silencing (De Lucia et al. 2008). LHP1, the Arabidopsis homolog of the metazoan HETEROCHROMATIN PROTEIN1 (HP1), is also required to maintain the epigenetic silencing, and intriguingly binds to $\mathrm{H} 3 \mathrm{~K} 27 \mathrm{me} 3$, rather than H3K9me3 as in mammalian cells (Fig. 2; Mylne et al. 2006; Sung et al. 2006a; Zhang et al. 2007).

\subsection{Cell-Autonomous Bistable Switching}

An unusual characteristic of the epigenetic silencing during vernalization is its quantitative nature: The degree of silencing is dependent on how much cold the plant perceives. This feature ensures the plant can distinguish a cold snap in autumn from a whole winter. Detailed analysis on whole tissue showed a quantitative cold-induced accumulation of $\mathrm{H} 3 \mathrm{~K} 27 \mathrm{me} 3$ at the FLC intronic nucleation site (Fig. 3A) (Angel et al. 2011). The quantitative nature is also reflected in the level of H3K27me3 over the body of the gene after transfer to warm. Mathematical modeling, constrained by the $\mathrm{H} 3 \mathrm{~K} 27 \mathrm{me} 3$ data, predicted that the quantitative nature of vernalization was generated by a cell-autonomous switch, in which the FLC locus flipped into a fully epigenetically silenced state, marked by high levels of H3K27me3 over the whole locus (Fig. 3B) (Angel et al. 2011). Lengthening cold would increase the proportion of cells that have undergone this switch (Fig. 3C). The prediction that vernalization is quantitative because of the degree of cells that flip was confirmed in transgenic plants carrying an FLC fusion that could be visualized at the cellular level: A bistable expression pattern was indeed verified in partially vernalized plants (see middle panel of Fig. 3C) (Angel et al. 2011). The quantitative increase is thus a reflection of an increasing proportion of cells with a fully epigenetically silenced FLC locus, rather than all cells carrying an increasingly silenced FLC.
The cold-induced nucleation of the PHD-PRC2 complex is a key regulatory step in the environmental induction of this process. However, the establishment of silencing still occurs in plants deficient for the PHD proteins (Swiezewski et al. 2009), so there must be multiple cold-dependent steps in the epigenetic silencing of FLC-some to establish silencing and others to induce the accumulation of epigenetic memory. These multiple, independent cold steps suggest there is not just one "thermometer" for vernalization but that temperature is perceived by a number of different steps.

A search for cold-induced steps required for establishment of the silencing showed an early and robust induction of antisense transcripts (termed COOLAIR) to FLC (Swiezewski et al. 2009). These antisense transcripts encompass the whole length of the sense transcript, are alternatively polyadenylated and alternatively spliced (Fig. 4) and they are an integral part of $F L C$ regulation both in the warm and in the cold (Hornyik et al. 2010; Liu et al. 2010). Increased use of the proximal poly A site in the antisense transcript is linked to reduction in transcription of FLC in the warm and cold (Swiezewski et al. 2009; Liu et al. 2010), in a mechanism that is independent of the PHD proteins. There is also, somewhat later, cold induction of an FLC noncoding sense strand (termed COLDAIR) from a cryptic promoter within FLC intron 1 that is required for targeting PRC2 to the FLC locus (Heo and Sung 2010).

\subsection{Adaptation to Different Climates}

Variation in various steps of the vernalization mechanism has played a major role in the evolution of different reproductive strategies. Arabidopsis thaliana accessions not requiring vernalization can reproduce multiple times a year. This rapid-cycling habit has evolved from independent mutations in FRIGIDA, an activator of FLC expression (Johanson et al. 2000; Gazzani et al. 2003; Shindo et al. 2005). Variation at Arabidopsis FLC itself only rarely accounts for the rapid-cycling habit (Werner et al. 2005). FLC variation, however, is a major factor contributing to the need for different winter lengths in A. thaliana accessions (Shindo et al. 2006). How winter length is determined is still unknown, but studies in Arabidopsis halleri growing in its native Japanese habitat have pointed to a temperature/ time-averaging mechanism that integrates temperature over a six-week period (Aikawa et al. 2010). The mechanistic basis of adaptation to different winters has been explored through analysis of Arabidopsis accessions. Those from the northern limit of its range (e.g., Lov-1 from Northern Sweden [latitude $62.5^{\circ} \mathrm{N}$ ]) initially silence FLC within the same time frame, yet need much longer periods of cold for the maintenance of full epigenetic silencing. 
A Duration of cold period
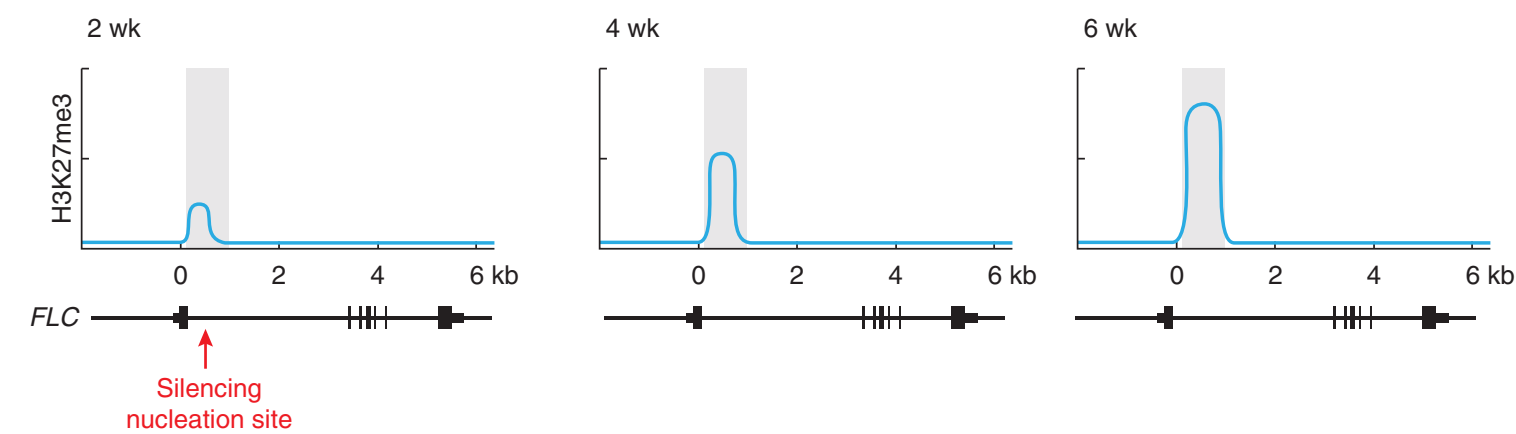

B Patterns of H3K27me3

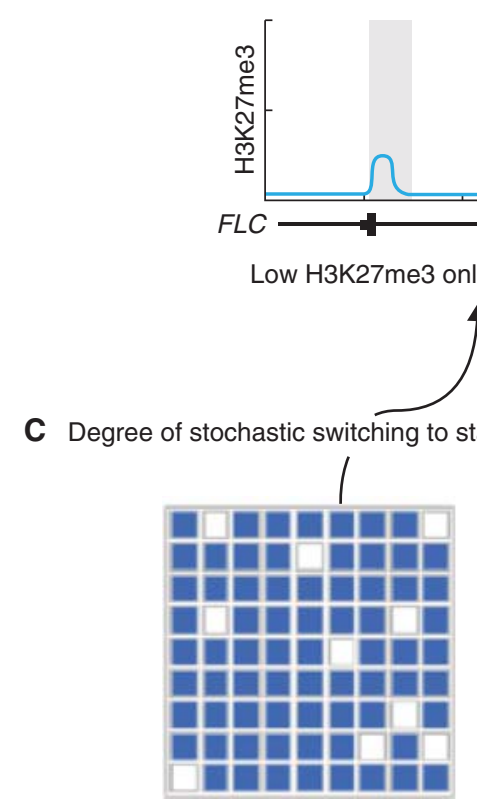

$2 \mathrm{wk}$

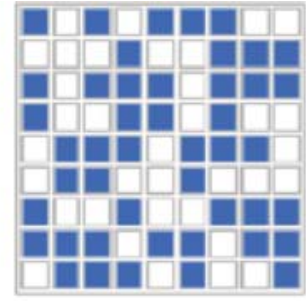

$4 \mathrm{wk}$

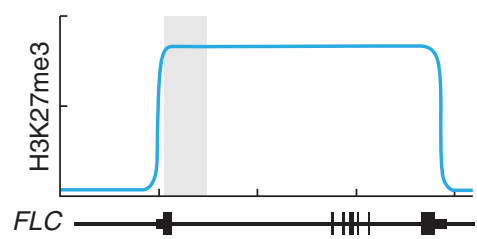

Switch to locus-wide H3K27me3
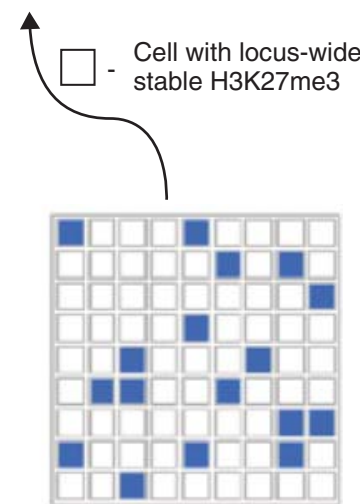

6 wk

Figure 3. Stochastic switching mechanism underlies the quantitative nature of vernalization. (A) During cold, H3K27me3 quantitatively accumulates in the nucleation region of the FLC gene, indicated schematically below each graph, with increasing weeks of cold (top row of figure). (B) After cold, the nucleated H3K27me3 causes some cells to switch to a silenced state with high levels of $\mathrm{H} 3 \mathrm{~K} 27 \mathrm{me} 3$ blanketing the gene. This epigenetic switch is cell-autonomous. $(C)$ The quantitative nature of the vernalization response is due to an increasing number of cells switching to a silenced state after increasing cold exposure. Each cell is indicated by a square. (Figure courtesy of Dr. Jie Song.)

Shorter cold leads to FLC expression resuming after transfer back to the warm (Fig. 5). A genetic analysis revealed that a major portion of this variation for winter length mapped to cis elements within FLC itself, and not the trans factors mediating vernalization (Shindo et al. 2006; Coustham et al. 2012). The natural variants are likely to provide important information on the cis elements and dynamics of the chromatin complexes that mediate both activation and repression of FLC.

This molecular variation in the epigenetic silencing also appears to apply to the molecular basis of perenniality (i.e., the ability to flower year after year). Analysis of Arabis alpina, a relative of Arabidopsis, revealed that the FLC homolog (called PEP1) shows interesting regulatory differences with FLC in A. thaliana (Wang et al. 2009). During prolonged cold, PEP1 expression in A. alpina plants decreases, enabling expression of downstream floral activators as in A. thaliana. However, unlike A. thaliana, the silencing is not epigenetically stable (Wang et al. 2009). Differences in epigenetic silencing thus seem to have contributed widely to the evolution of reproductive strategies in land plants. 
D.C. Baulcombe and C. Dean

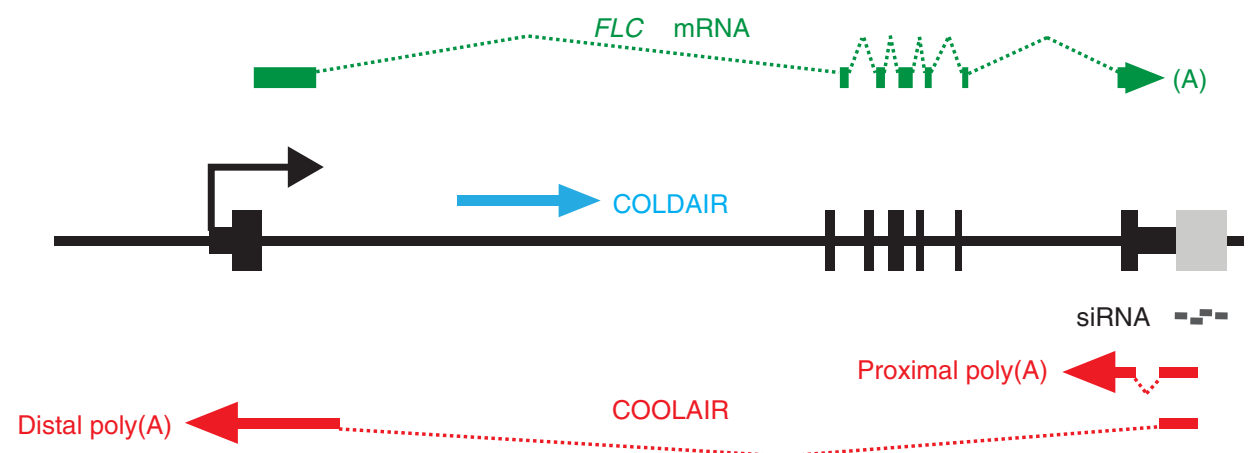

Figure 4. Noncoding transcripts at the FLC locus. Many classes of noncoding transcripts have been characterized at the FLC locus. A set of antisense transcripts have collectively been called COOLAIR (red). These are alternatively spliced and alternatively polyadenylated, and encompass the whole length of the sense transcript. They are an integral part of FLC regulation both in the warm and in the cold. An FLC noncoding sense transcript, termed COLDAIR (blue), is transcribed from a cryptic promoter in intron 1. There are also homologous 24- and 30-mer siRNAs (gray) mapping just upstream of the COOLAIR transcription start site.

\section{CASE HISTORY II-VIRUS-INDUCED GENE SILENCING AND EPIGENETICS}

In a second case history we describe an example in which the external stimulus is a virus and the maintenance mechanism is associated with RNA silencing and DNA methylation. This viral mechanism illustrates the potential for endogenous genome elements to initiate persistent gene silencing if they are activated by stress or other external stimuli.

\subsection{RNA Silencing in Virus-Infected Plants}

As an introduction to virus-induced epigenetic modification, we first describe the process of RNA silencing that is part of the antiviral defense systems in plants and inverte-

A

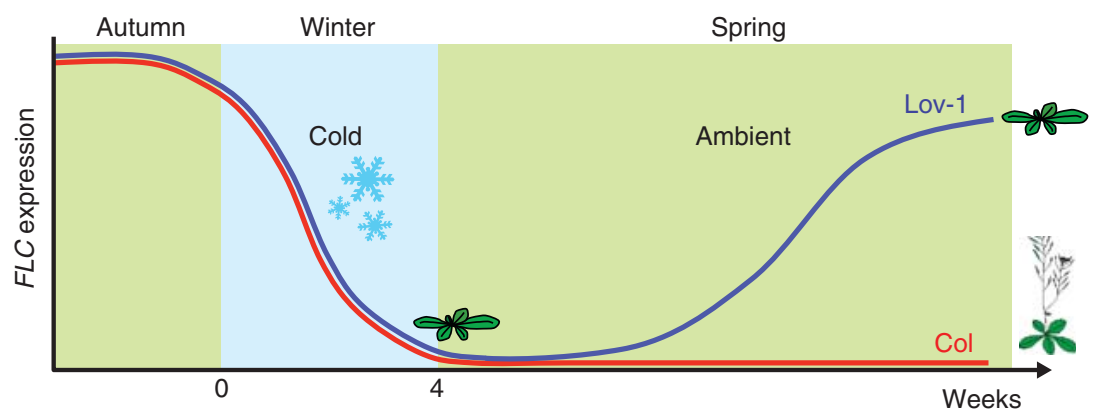

B

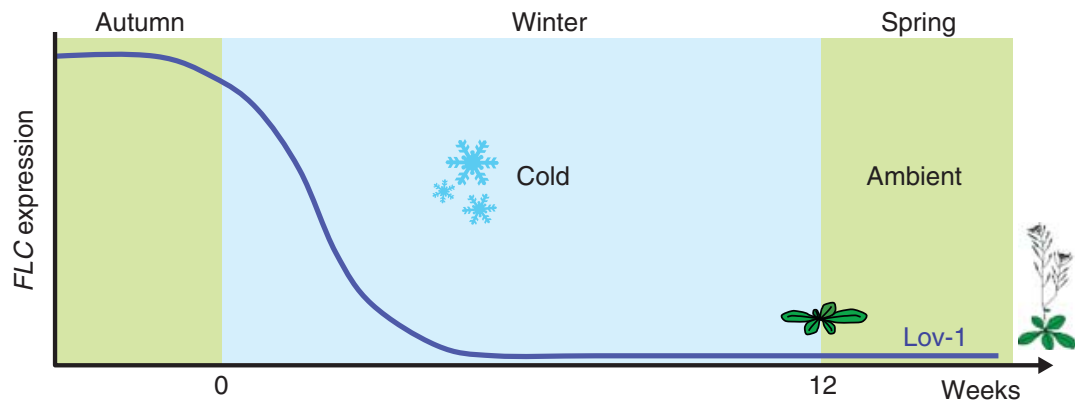

Figure 5. Quantitative variation in the epigenetic silencing of FLC in Arabidopsis accessions from different climates. (A) An Arabidopsis accession from Germany (Col, red line) requires only 4 wk of cold to epigenetically silence FLC. Lov-1, from the northern limit of its range in Northern Sweden (latitude $62.5^{\circ} \mathrm{N}$ ), sees reactivation of the FLC gene if the cold period is so short, resulting in an inability to become vernalized and, hence, does not flower. (B) Lov- 1 needs a much longer period of cold (12 wk) for full epigenetic silencing. Molecular analysis has shown this difference is the result of a small number of cis polymorphisms near the PHD-PRC2 nucleation region in intron 1. 
brate animals (Baulcombe 2004). RNA silencing operates when plant cells recognize the viral RNAs as foreign and copy it with an RNA-dependent RNA polymerase (RdRP) into a double-stranded ( $\mathrm{ds}$ ) form. The double-stranded RNA (dsRNA) is then processed by a Dicer nuclease into 21-24-nt siRNAs (Dunoyer and Voinnet 2005). In plants, the Dicer proteins are referred to as Dicer-like (DCL) although strictly they are not DCL-they are, in fact, Dicer proteins. The small RNAs are initially in a ds form but eventually a single-stranded (ss) version is then incorporated into an effector ribonucleoprotein complex that also contains an Argonaute (AGO) nuclease (Fig. 6A). AGO has structural similarity to ribonuclease $\mathrm{H}$ and the siRNA serves as a guide for AGO: The siRNA is able to base pair with other RNAs in the cell and thereby guide AGO to its target for degradation or to be translationally suppressed. The rule for targeting is to have base-pairing between the siRNA and its target at most of the 21-24 positions. The most frequent target of viral siRNAs would, of course, be the viral RNA itself (Dunoyer and Voinnet 2005).

A

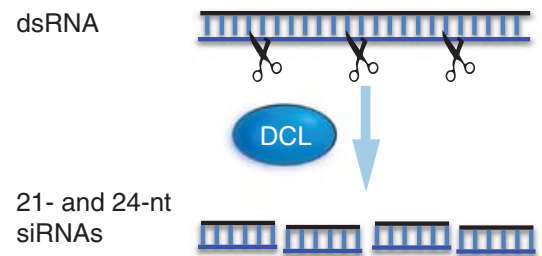
siRNAs
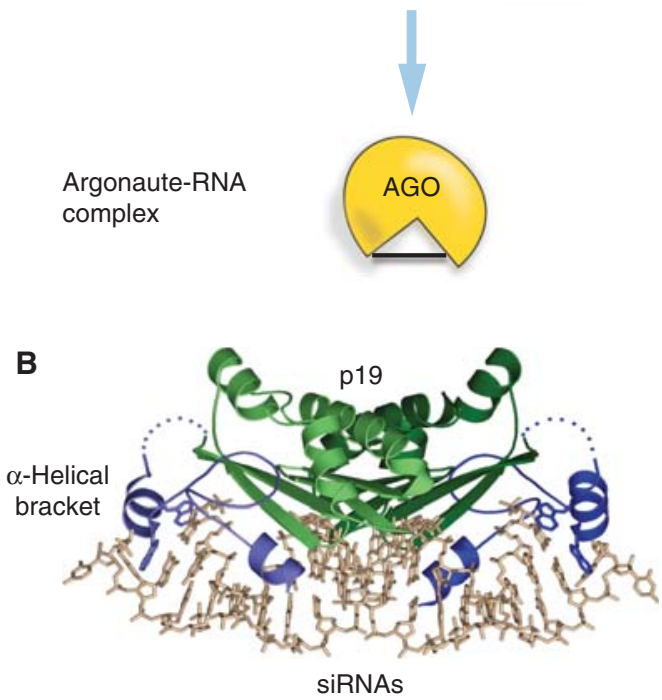

Figure 6. Virus- and transgene-induced RNA silencing in plants. $(A)$ The core RNA silencing pathway: dsRNA is processed into 21-nt and 24-nt RNA by Dicer and then bound to the Argonaute slicer protein, to guide the complex to specific target RNA sequences. (B) The p19 viral suppressor of RNA silencing (VSR): The siRNA (stick diagram) is bound to a dimeric form of the p19 viral suppressor and held in place by helical brackets formed by the respective amino termini. ( $B$, Reproduced from Vargason et al. 2003, with permission from Elsevier.)
In an uninfected cell there are no viral siRNAs, hence AGO proteins have no guides to target viral RNAs. Thus, following infection, the first few rounds of virus replication would be unconstrained by RNA silencing. However, once the viral RNA has accumulated to a substantial level it could prime AGO and the rate of viral RNA accumulation would slow down. The steady state level of virus accumulation would be a reflection of the relative kinetics of silencing and the rate of virus accumulation. The steady state levels are also influenced by the extent to which the viral RNA can evade the silencing machinery by, for example, encapsidation (Baulcombe 2004), or through the action of VSR (Ding and Voinnet 2007).

VSRs can act by binding to siRNA or proteins of the RNA silencing pathway, directly or indirectly, effectively sequestering them to prevent the viral RNA from being targeted. One of the best-understood suppressors is a 19$\mathrm{kDa}$ protein ( $\mathrm{p} 19)$ from tombuviruses that forms a dimeric clamp around the ds form of siRNA (Fig. 6B) (Vargason et al. 2003). The two p19 amino termini are positioned precisely around the two ends of the RNA duplex structure so that the two strands of the duplex cannot separate and release the active ss form. Other well-understood VSRs include P38 from carmoviruses that binds the AGO protein itself via a glycine-tryptophan (GW) hook motif (Azevedo et al. 2010), and $\mathrm{P} 0$ from poleroviruses that is an atypical $\mathrm{F}$ box protein that directs AGO degradation through an autophagy rather than the normal proteasome pathway (Derrien et al. 2012).

There are probably very few, if any, plant viruses that do not trigger RNA silencing in one form or another although there may be subtle differences. The RdRP step, for example, can be bypassed if the viral RNA has base-paired regions in foldback structures or, in viruses with circular DNA genomes, the dsRNA is formed by annealing of complementary RNAs transcribed from opposite DNA strand. The AGO step can also be dispensed with if the viral RNA exists in a ds form, allowing Dicer to act directly as the antiviral nuclease (Ding and Voinnet 2007).

RNA silencing operates in animals and plants, and the virus defense system described above is probably related to a primitive RNA silencing pathway that existed in primitive eukaryotic cells. Defense against viruses is likely to have been an essential function in this ancient cell type and it is likely that it used RNA silencing in a defense role, as in modern plants. RNA silencing might even be a vestige of the RNA world that is thought to have existed before DNA acquired its central role in inheritance (Salgado et al. 2006).

Since the divergence of animals and plants, it seems that RNA silencing pathways diversified in the different lineages of animals, plants, fungi, and other eukaryotic organisms. The end result is a number of variations on the RNA si- 
lencing theme in different organisms (also discussed in Martienssen and Moazed 2014). These variations involve endogenous genetic elements including genes as well as viruses and transposons (Zamore 2006).

\subsection{Multiple RNA Silencing Pathways}

The diversity of RNA silencing mechanisms is very evident in plants (Eamens et al. 2008). The small RNAs in these pathways are referred to as either microRNAs (miRNAs) or siRNAs depending on the structure of their precursor (Fig. 7). The miRNAs are derived from a precursor RNA containing an inverted repeat structure whose two arms fold back on each other to form a base-paired structure that is the substrate for Dicer. A key feature of these RNAs is the mismatches that occur between the two arms of the foldback region that guide the Dicer nuclease to a single site in the foldback structure. Each precursor RNA of this type therefore generates a single miRNA that associates, as described above, with AGO. Most miRNAs are $21 \mathrm{nt}$ although there are 22-nt and 24-nt forms. They are normally implicated in posttranscriptional silencing; The AGO nuclease either cleaves a target messenger RNA (mRNA) or blocks its translation through a mechanism that is not understood.

The siRNAs are generated by Dicer from precursors that, in contrast to the pre-miRNAs, are perfectly basepaired (Fig. 7). The absence of mismatched structures means that Dicer has no guide. It either cleaves randomly in the base-paired region or processively from one end. If cleavage is initiated from one end, the siRNAs are predominantly in the same register and phased (Chen et al. 2007;

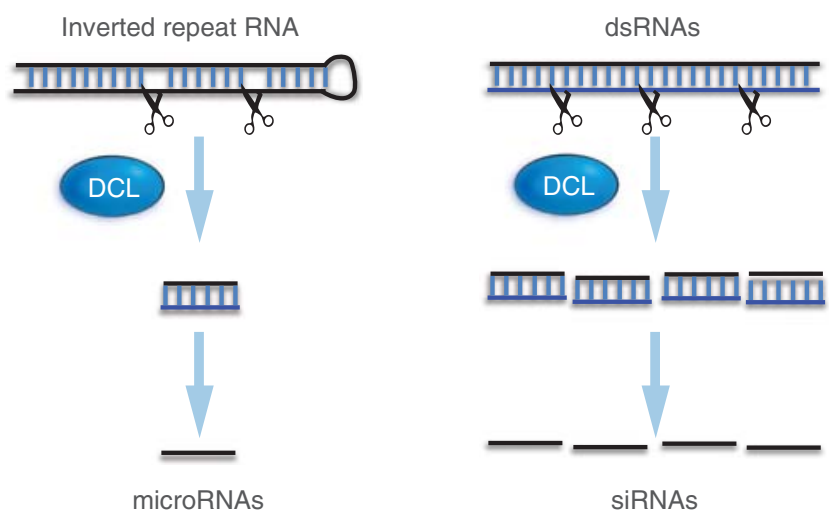

Figure 7. Endogenous RNA silencing in plants. The difference between miRNAs and siRNAs: miRNAs are generated by DCL cleavage of a single RNA molecule in which there is a secondary structure. Mismatches in base-paired regions guide the DCL protein so that it releases a single miRNA from the long precursor. In contrast, the siRNAs are derived from a perfectly base-paired precursor molecule that is cleaved at several sites to release multiple siRNAs.
2010). However, irrespective of whether the siRNAs are phased (Chen et al. 2010), multiple siRNAs can be generated from a single precursor. The existence of single or multiple short RNAs from a single precursor is a fundamental difference between miRNAs and siRNAs. Both host and viral genomes can generate siRNAs. siRNA precursors, which are ds, can be generated either by RdRP transcription of an ss template, the annealing of complementary RNAs, or foldback and base-pairing of inverted repeat regions as described above for virus-infected cells (Figs. 7 and 8).

Although there are several small RNA pathways in animals, the potential for diversity is more pronounced in plants. This difference between plants and animals is probably a consequence of the extreme plasticity of plant genomes that have facilitated the duplication and neofunctionalization of Dicer, AGO, and other RNA silencing factor genes. In flowering plants, genome plasticity accounts for more than a 1000-fold difference in range of haploid genome size between different species. This large range of genome sizes is due to repeated rounds of whole genome duplication, the activity of transposable elements, but also reductions in genome size due to genome deletions. The net result of this genomic flux is that many proteins in modern plants, not only those in RNA silencing, are encoded in multigene families (Van de Peer et al. 2009).

Plant Dicers provide one of the best examples of functional diversification within a gene family. These multigene families encode four or more members, depending on the species, and the different forms of DCL are functionally distinct (Gasciolli et al. 2005). Some Dicers generate 21nt molecules that are involved in posttranscriptional silencing, as described above with miRNAs. They can produce both miRNAs and siRNAs. Other Dicers generate 22-nt siRNA or miRNAs that somehow influence the structure of the associated AGO so that the targeted RNA is converted into a ds form by an RdRP (Chen et al. 2010; Manavella et al. 2012). This dsRNA is then processed by Dicers to generate secondary siRNAs that associate with AGO proteins and participate in further rounds of targeting through RNA cleavage, translational arrest or RdRP recruitment (see Fig. 7 in Pikaard and Mittelsten Scheid 2014). The consequence of this secondary siRNA pathway is to amplify the RNA silencing effect: A single 22-nt initiator siRNA or miRNA gives rise to many secondary siRNAs and a regulatory cascade (Chen et al. 2007).

A third class of Dicers generates 24-nt siRNAs (Xie et al. 2004). Like their shorter relatives, these 24-nt siRNAs associate with AGOs. However AGOs, like Dicers, are encoded by multigene families and they are functionally diverse (Havecker et al. 2010). The AGOs associating with 24-nt siRNAs, for example, are different from those that bind to 21- or 22-nt siRNAs; they act in the nucleus rather than the 


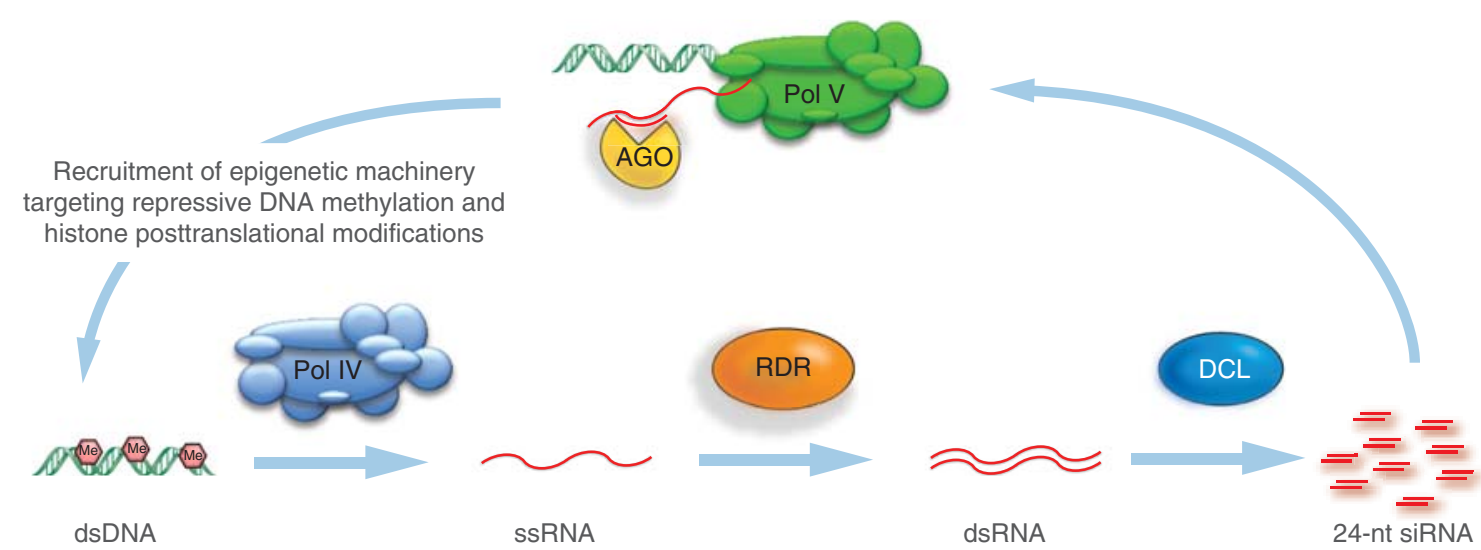

Figure 8. The Pol IV pathway of siRNA biogenesis. The variant form of RNA polymerase II (Pol II), known as Pol IV, generates single-stranded RNA (ssRNA) from a DNA template. The ssRNA is converted to a ds form by RdRP and then processed into 24-nt siRNAs by a DCL protein. The siRNA then binds to an AGO protein and it targets nascent transcripts in noncoding regions of the genome that are transcribed by a second variant form of Pol II known as Pol V. The AGO protein then recruits DNA methyltransferases to introduce methyl groups at cytosine bases (pink hexagon symbols) of the DNA template as well as other histone-modifying enzymes.

cytoplasm and they affect epigenetic modification of DNA or chromatin rather than mRNA (see Fig. 3 in Pikaard and Mittelsten Scheid 2014).

This 24-nt RNA-directed epigenetic silencing mechanism is similar to posttranscriptional silencing because the AGOs are involved, and the specificity of targeting is due to Watson-Crick base-pairing of the siRNA. However, the role of the 24-nt siRNAs is distinct because they target a chromatin-associated RNA rather than an mRNA (Wierzbicki et al. 2008). This chromatin RNA is transcribed by an atypical form of DNA-dependent RNA polymerase II, known as Pol V (Fig. 8). The AGO proteins bound to 24-nt siRNA are distinct from those with 21-nt of 22-nt siRNAs because they guide the DRM2 DNA methyltransferase (Law and Jacobsen 2010). DRM2 introduces methyl groups onto $\mathrm{C}$ residues in DNA when it has been targeted to a region of DNA by an AGO complex so that the 24-nt siRNA is, in effect, the determinant of genomic regions that are to be methylated by DRM2. The involvement of DNA methylation gives this pathway an epigenetic property. This is discussed in detail in Section 3.5.2 of Pikaard and Mittelsten Scheid (2014) and illustrated in Figure 6 of their article.

\subsection{Virus-Induced Silencing of Promoters}

The different RNA silencing pathways described in Section 3.2 are relevant to the epigenetic case history of virus-induced promoter silencing because viral siRNAs include the 24-nt-long species (Deleris et al. 2006) that have been implicated in epigenetic silencing, as described above. The smaller 21- or 22-nt species are also produced from viral RNA, but they are associated with posttranscriptional gene silencing. These smaller siRNAs are important in defense, particularly against RNA viruses.

Virus-induced posttranscriptional gene silencing is illustrated very clearly by an experiment with transgenic plants expressing the green fluorescent protein under the control of a strong plant viral promoter, called 35S (Fig. 9). These plants were green fluorescent under UV light. If these plants were then infected with an RNA virus that had been modified to carry a part of the green fluorescent protein (GFP) coding sequence (Fig. 9B), the GFP fluorescence faded and the GFP mRNA was degraded through the siRNA- and AGO-based mechanism described above (Fig. 6). The virus used in this experiment did produce a weak VSR (Martin-Hernandez and Baulcombe 2008), but clearly it could not completely block the virus-induced silencing of the GFP transgene in the infected plants.

Virus-induced posttranscriptional silencing affects the host if, by chance, a virus or virus-associated nucleic acid has sequence similarity to a host mRNA. The viral siRNAs target the host gene and the symptoms of the infected plant reflect a corresponding loss-of-function (Shimura et al. 2011). Viral silencing is also a useful technology in functional genomics (Baulcombe 1999); the basic idea is simply to produce a library of viral clones with inserts corresponding to different host genes. Plants are then infected with individual clones and monitored for symptoms in the expectation that they would reflect the function of the gene insert. This approach has been very successful, for example, in the identification of genes required for disease resistance (Lu et al. 2003).

An epigenetic rather than posttranscriptional effect of the virus-derived 24-nt siRNA is also illustrated by the use of 
D.C. Baulcombe and C. Dean

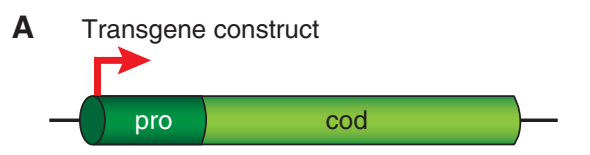

\section{B}
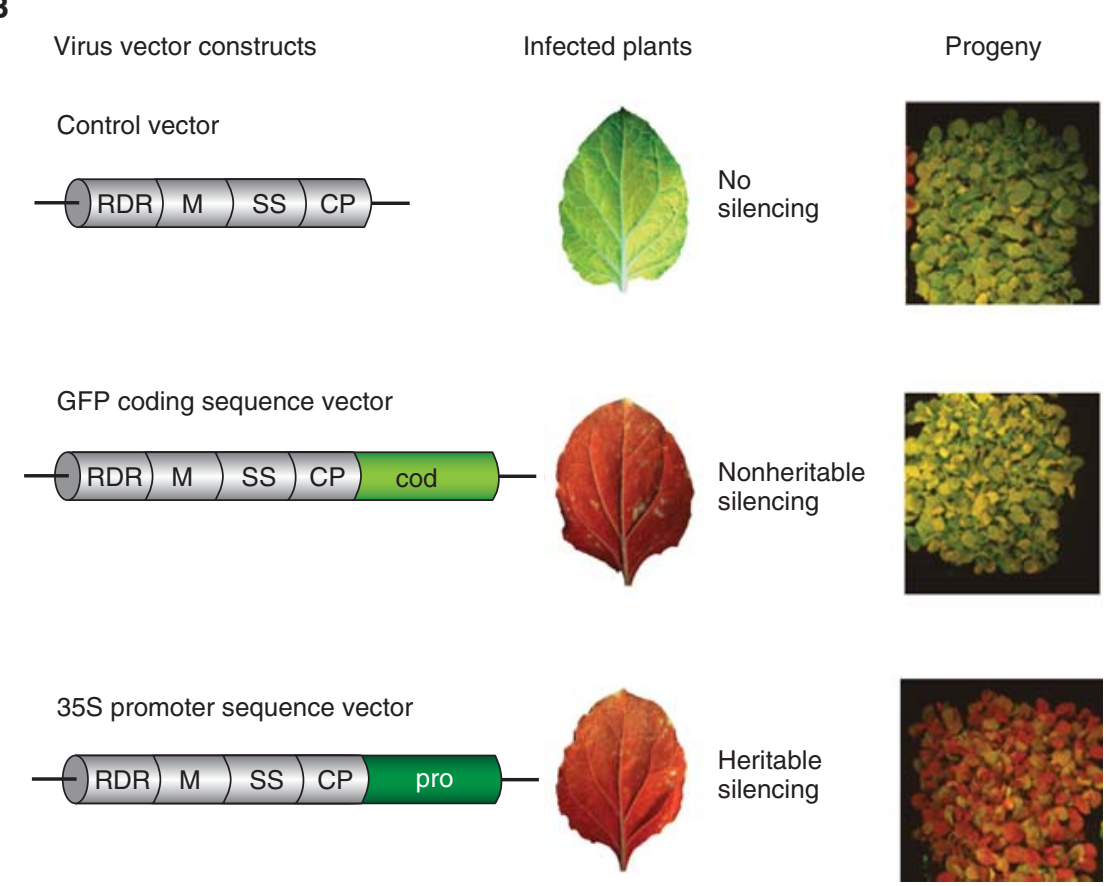

Figure 9. Virus-induced gene silencing-VIGS. A demonstration of VIGS in Nicotiana benthamiana, a plant related to tobacco, carrying an endogenous copy of a transgene construct $(A)$ containing a $35 \mathrm{~S}$ promoter ( pro) driving GFP coding sequences (cod). $(B)$ The tobacco rattle virus vector constructs are replicating RNA molecules that encode several proteins. The proteins include a viral RNA-dependent RNA polymerase (RDR), a movement protein (M), a suppressor of silencing (SS), and a coat protein (CP). The control virus vector (top) has no insert. The experimental constructs carried an insert corresponding either to "pro" or "cod." The loss of green fluorescence in the plants infected with the experimental constructs indicated that there was gene silencing using both constructs (center); however, with the pro construct, silencing persisted into the progeny seedlings (right side).

GFP transgenic plants. For epigenetic silencing, the insert in the virus vector must correspond to the transgene promoter rather than the coding sequence. The infected plants show loss of GFP with virus constructs carrying promoter or coding sequence inserts (Fig. 9B). However, heritable GFP silencing is caused by targeted methylation of the DNA of the associated gene (in this case, the integrated transgene).

This transcriptional gene silencing (TGS) mechanism can also target endogenous plant genomic elements if there is sequence similarity between the virus and the plant genome. This occurs because $\mathrm{C}$ residues in the endogenous promoter become methylated in the infected plant, blocking transcription of its adjacent gene. There was transcriptional silencing and promoter DNA methylation, for example, when the GFP transgenic plants described above were infected with a tobacco rattle RNA virus carrying part of the $35 \mathrm{~S}$ promoter sequence in an RNA form (Fig. 9) (Jones et al. 2001).
The mechanism of gene silencing has not been explored in the tobacco rattle virus experiments but, based on other epigenetic systems in plants, it is likely to involve the DRM1/2 DNA methyltransferases (Dnmt homologs) and histone-modifying enzymes including histone deacetylases and lysine methyltransferases. Acetylation of lysine residues weakens the binding of histones to DNA so that there is less resistance to the translocation of RNA polymerase. Methylation of lysines, particularly at histone $\mathrm{H} 3$ lysine 9, is similarly correlated with silent chromatin (Fig. 8).

\subsection{Separate Establishment and Maintenance of Virus-Induced Gene Silencing}

Epigenetic mechanisms are classically defined when they persist through cell generations even if the initiation stimulus is transient. This defining feature of epigenetic regulation is clearly illustrated by the persistence of GFP 
silencing in the progeny of viral infected plants possessing the pro insert (Fig. 9B) (Jones et al. 2001). The viral constructs in these GFP experiments are designed to not transmit the virus through the seed, so the different generations provide clear separation of establishment and maintenance of the silencing phenotype; that is, establishment of silencing in the infected plant is clearly dependent on the virus whereas maintenance in subsequent generations is virusindependent. The transcriptional silencing observed using viral constructs containing $35 \mathrm{~S}$ promoter homology was truly epigenetic because it persisted in several generations of virus-free progeny. In contrast, the experiments with the GFP coding sequence virus showed no silencing in the next generation (Fig. 9B). The persistence of posttranscriptional silencing is, therefore, dependent on the presence of the initiator virus and the effect is not epigenetic.

The difference between the establishment and maintenance phases arises because DNA methylation in TGS can be maintained, at least partially, in the absence of the initiator virus by maintenance DNA methyltransferase activity that is distinct from the de novo enzymes involved in establishment. The methyltransferase MET1, for example, causes $\mathrm{C}$ residue methylation to be replicated if the $\mathrm{C}$ is adjacent to a $\mathrm{G}$ on its $3^{\prime}$ side (Fig. 10). The daughter strand is methylated on the $C$ residue opposite to this $G$ and, following the same pattern in a second round of replication, the methylation is added to a $\mathrm{C}$ in the original position. Such a mechanism does not, of course, maintain methylation at $C$ residues that are not adjacent to $G$, and so the extent of DNA methylation in the maintenance phase of an epigenetic mechanism is less extensive than in the presence of the initiator.

This distinction of initiation and maintenance phases is central to many epigenetic phenomena including those in which the mechanisms do not involve DNA methylation. In the vernalization case history described above, for example, the initiation phase is the nucleation of the PHD-PRC at the intronic site in FLC and maintenance is associated with the complex spread and LHP1 function.

\subsection{Mobile Silencing}

Maintenance of epigenetic effects in plants is effective if the initiator stimulus is applied to the meristems. The silenced state can then be passed to new cells, tissues, and organs as they arise. In vernalization, for example, the cold stimulus is perceived in meristems and the silenced state of FLC is propagated with the replication of chromatin as the cells divide. However, there are also instances in which initiation and maintenance are in separate cells and there are mobile signals that move between cells (the topic of Dunoyer et al. 2013).

In instances of epigenetic RNA silencing, mobile signals were illustrated by experiments in which shoots from one genotype of plant were grafted to another (Fig. 11) (Melnyk et al. 2011). One illustrative experiment was based on plants in which a GFP target transgene was expressed under the control of a meristem-specific promoter and enhancer, and in which a silencer transgene was designed to produce siRNA to target the necessary enhancer component. The target transgene was methylated at $\mathrm{C}$ residues and silenced in root meristems if they were grafted to shoots carrying the silencer. However, this promoter DNA methylation and silencing did not occur if the silencer shoots were defective for the 24-nt siRNA-specific Dicer. Correspondingly, the 24-nt siRNAs were present in the grafted root if the shoot was from the wild type but not Dicer mutant shoot. These and other experiments illustrated clearly that 24-nt siRNAs
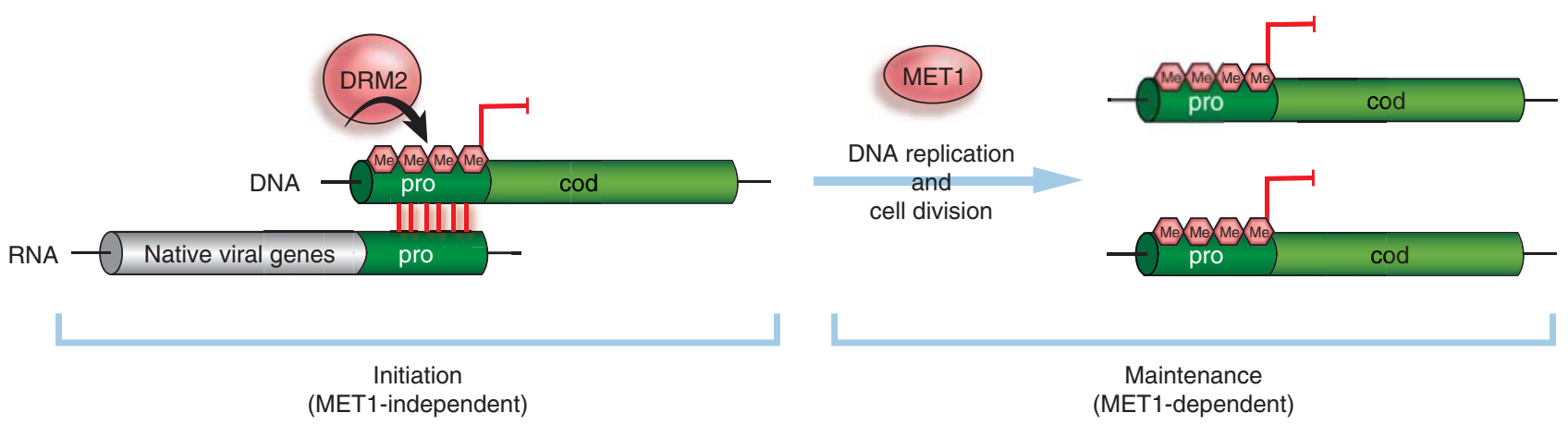

Figure 10. Separate establishment and maintenance of transcriptional silencing induced by a virus. The red vertical lines represent the interaction between the viral RNA containing the promoter sequence insert (pro) and the cognate DNA. The promoter DNA is assumed to be the target of the RNA silencing pathway to which methyl groups are introduced (Fig. 8). TGS initially occurs through de novo DNA methylation (pink hexagon symbols) of the promoter sequence, catalyzed by DRM2. Maintenance of silencing relies on the maintenance DNA methyltransferase, MET1 propagating methylation patterns through DNA replication and cell division. 


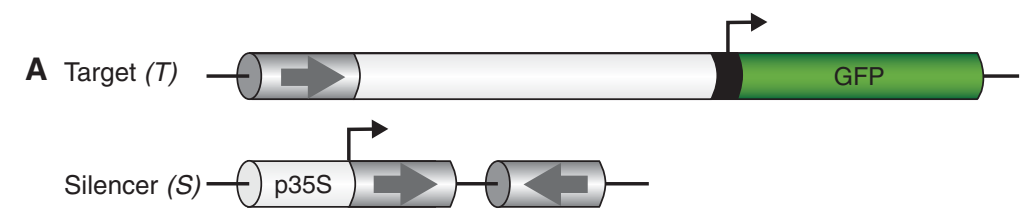

B
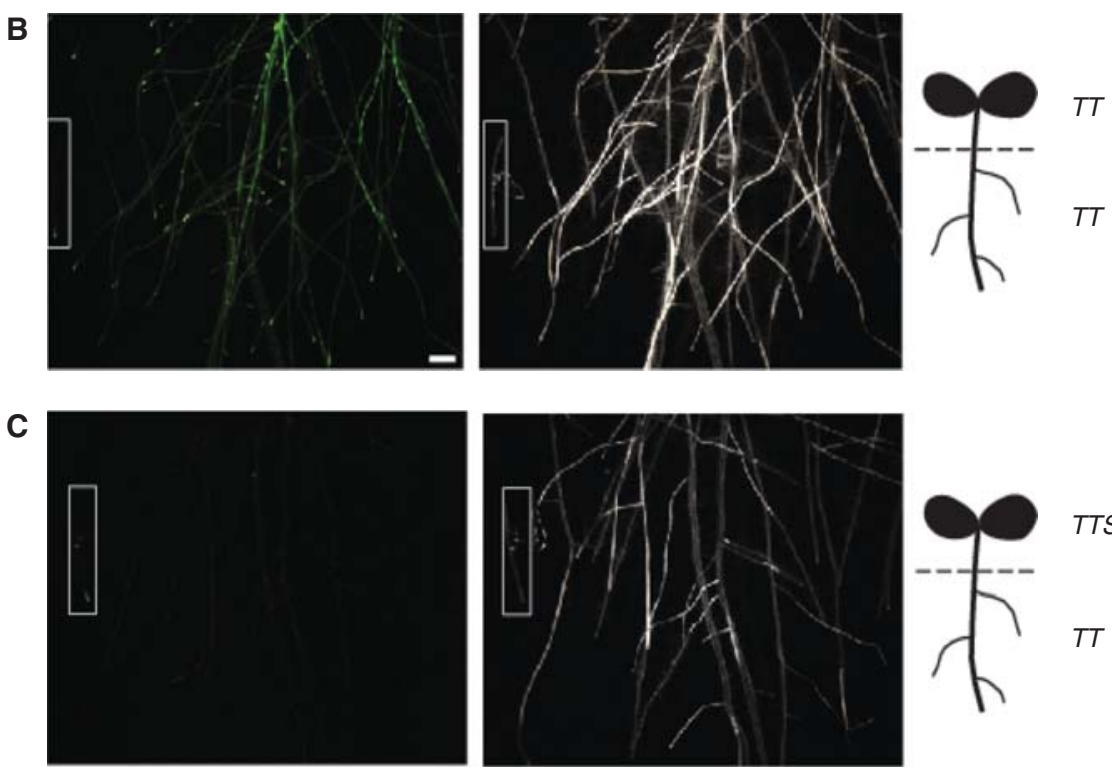

TTSS

$T T$

Figure 11. An experiment to show mobile silencing. (A) Plants carrying the target GFP transgene coupled to a promoter with meristem-specific enhancer region (arrow) are denominated TT, and were hybridized to SS plants carrying a silencer construct with a $35 \mathrm{~S}$ promoter that directed transcription of an inverted repeat of the enhancer (arrows). The TT $(B)$ and TTSS plants $(B)$ were grafted as a shoot scion to the TTroots and the expression of GFP was monitored by GFP fluorescence and RNA gel blotting to track spread of silencing from the shoot into the root. In this analysis the panels shown in $B$ and $C$ are images of the roots under UV (left) or white (right) light. TTSS shoot grafts cause GFP silencing in the roots, indicating the mobile nature of the silencing signal. (Adapted from Melnyk et al. 2011.)

are the mobile signals in plants and that they can initiate epigenetic effects in recipient meristems (Molnar et al. 2010; Melnyk et al. 2011; described in Dunoyer et al. 2013).

\section{RESETTING VERSUS TRANSGENERATIONAL INHERITANCE}

These two case histories illustrate examples of environmentally induced epigenetic change that are fundamentally different. Vernalization involves Polycomb group proteins, is independent of DNA methylation, and is reset in each generation. The resetting is important as an environmental response: Plants with a vernalization requirement have to experience an appropriate cold period (winter) in each generation before they will flower. Virus-induced transcriptional gene silencing, in contrast, is dependent on DNA methylation, is targeted by siRNA, and persists between generations.

Currently, we do not understand the mechanism that ensures that methylation marks at promoter DNA persist through meiosis, gametogenesis and early embryogenesis. In fact, we do not understand the broader question of why some epigenetic marks are heritable whereas others are not. In part the difference could be associated with the different types of epigenetic marks: Polycomb marks could be more prone to resetting whereas DNA methylation is more likely to be transmitted between generations. However, this cannot be the whole story because many DNA methylation marks, including those that are set by viruses, are sometimes lost in the next generation (Kanazawa et al. 2011; Otagaki et al. 2011). The persistent marks may have more or particular types of methylated $\mathrm{C}$ residues and be more difficult to erase than those that are reset. Alternatively, it could be that heritable epigenetic marks generate a signal that is transmitted from the maternal plant to the progeny, which guides reestablishment in the early zygote or meristematic cells of the next generation.

Evidence in support of the latter model derives from an analysis of transposon silencing in the pollen of Arabidopsis. The transposon marks are lost in the somatic cell of the 
pollen so that transposons are activated. RNA from the active transposons serves as a precursor of siRNA production that is then transported into the germ cells of the pollen grain. These cells then fertilize the egg cell and give rise to the next generation. In addition, they carry the mobile siRNA into the fertilized egg so that it can reinforce the establishment of epigenetic marks in the zygote (Slotkin et al. 2009; further discussed in Dunoyer et al. 2013).

\section{TRANSIENT EPIGENETIC REGULATION IN RESPONSE TO STRESS}

The two case histories of environmentally induced epigenetic regulation are well understood at the molecular level. However, there are many other examples of effects in plants that may have an epigenetic basis including those that are induced by stress.

One of these candidate epigenetic phenomena is wellknown to gardeners who "harden off" plants by a mild exposure to low temperature so that they are then protected against later freezing temperatures. Of course, this process needs to be repeated in each generation. The concept of deficit irrigation, in which long-term drought tolerance can be induced by transient or partial drying, could similarly be explained in terms of epigenetic mechanisms that are reset in each generation (Davies et al. 2010). Epigenetics is invoked in these two examples because the response persists for an extended period after the initial induction; that is, there is a molecular memory that is unlikely to involve mutation or other types of genome alteration. Other stresses appear to be less effective than temperature or drought at inducing epigenetic changes, although exposure of Arabidopsis to UV irradiation may induce a long-lived increase in somatic recombination (Molinier et al. 2006).

The mechanisms underlying these phenomena are still being elucidated. In principle, self-reinforcing mechanisms such as autoregulatory transcription factors (Ptashne 2007) could play a role. However, there is good evidence that chromatin- and RNA-based mechanisms are involved, as described above. Early work showing a role of temperature in siRNA production hinted at a role for RNA in this environmental memory (Szittya et al. 2003). Other studies revealed changes in nucleosome spacing and transient chromatin decondensation following exposure to different high temperature regimes (Pecinka et al. 2010). With mild increases in temperature, there is evidence that H2A.Z may act as a thermosensor (Kumar and Wigge 2010). This histone $\mathrm{H} 2 \mathrm{~A}$ variant is normally associated with transcription start points.

Most of these temperature-sensitive chromatin changes and the associated up- or down-regulation of gene expression are transient. However, the transcripts of a COPIA 78 retrotransposon family were enhanced for up to $7 \mathrm{~d}$ after exposure to stress. This effect was independent of DNA demethylation or changes to histone H3K9 methylation, but it was affected by siRNA pathways. One interpretation of these results is that, as a result of siRNA action, an epigenetic mark may constitute the way nucleosome loading occurs rather than direct chemical modification of the DNA or chromatin (Ito et al. 2011).

A longer-lived epigenetic "memory" occurs following exposure of plants to various pathogens. The initial exposure to the pathogen may activate defense systems involving hormones including salicylic acid, and genes that interfere with growth of the pathogen. The primary responses are, however, transient, but if the plants are then exposed to a second pathogen, the genes are activated more rapidly than after the first inoculation. A similar defense priming effect is induced by $\beta$-amino butyric acid.

This defense priming memory persists for $28 \mathrm{~d}$ or even longer. The possibility that pathogen-induced changes are epigenetic is further reinforced by the extensive and dynamic changes to the methylation of genomic DNA in Arabidopsis infected with bacteria or treated with the defense hormone salicylic acid (Dowen et al. 2012). The key changes may involve loss of DNA methylation at defense gene loci so that they are more easily activated at the transcriptional level (Yu et al. 2013).

\section{TRANSGENERATIONAL EPIGENETIC REGULATION IN RESPONSE TO STRESS}

The examples of stress-induced effects discussed in the previous section are mostly transient. However, the virusinduced gene silencing case history illustrates the potential for transgenerational epigenetic effects in plants if a stress induces siRNAs or chromatin changes. There are several intriguing observations that are consistent with this prediction. In Mimulus, for example, artificial herbivory induces heritable alterations in expression of a gene controlling trichome production and, correspondingly, transgenerational changes in trichome density (Holeski et al. 2010). In dandelions (Taraxacum officinale), the genomewide pattern of DNA methylation is modified if the parental plants are exposed to environmental stress and the progeny show modifications of root/shoot biomass ratio, $\mathrm{P}$ content, leaf morphology, and stress tolerance relative to the control. DNA methylation is implicated because chemical suppression of DNA methyltransferase blocks the transgenerational effects (Verhoeven and Van Gurp 2012).

A third example involves rice plants subjected to the stress involved in regeneration from tissue culture. The regenerated plants had changes to the genome-wide pat- 
tern of DNA methylation, including some at the promoters of genes. The changes are predominantly loss rather than gain of DNA methylation and they persist in the regenerated plants and their progeny (Pellegrini et al. 2013).

These miscellaneous examples should be taken as indicators rather than proof of transgenerational epigenetic change affecting an adaptive phenotype. None of these examples provide definitive evidence that changes to gene expression and/or the epigenome are causal of phenotypic changes; there are either no phenotypes or the evidence is correlative. In T. officinale, in addition, the seeds are produced apomictically (i.e., asexually, without meiosis) and the mechanisms may not represent those that apply in sexual reproduction.

However, there is one example related to defense priming in which there is good evidence for a transgenerational epigenetic effect that could be adaptive (Luna et al. 2012). The progeny of Arabidopsis plants infected with bacteria were more resistant to secondary infection with an oomycete (fungi-like unicellular organisms) than the control progeny of unprimed plants. This effect was evident in the first-generation progeny, as with the phenomena described in the previous paragraph. However, oomycete resistance was also present in the second-generation progeny that were produced on plants that were not themselves primed by infection. This observation is crucial because it rules out inherited resistance being due to the transport of a physiological or biochemical factor from parents to seed-the most likely explanation is therefore epigenetic.

Chromatin analysis of defense genes has reinforced the notion that inherited priming is because of epigenetic mechanisms. Defense genes that are up-regulated following primed resistance were associated with the enrichment of acetylated histones-a known activating epigenetic mark-in the promoter region. In contrast, down-regulated genes following primed resistance had higher levels of the repressive mark H3K27me3. However, this is not a simple mechanism because plants that were defective for DNA methylation at $\mathrm{CpHpG}$ sites mimicked the transgenerational priming (Luna and Ton 2012). It is likely, therefore, that transgenerational priming is mediated by hypomethylation of DNA at these $\mathrm{CpHpG}$ sites; there may be cascades of epigenetic regulation in which stress leads to a loss of repressive marks that, in turn, trigger activating epigenetic marks.

\section{EPIGENETIC EFFECTS ON GENOME STRUCTURE}

Epigenetic mechanisms are linked in various ways to genome structure and there are several indications that envi- ronmental stimuli induce epigenetic mechanisms with genetic consequences. For example, there is evidence that DNA repair is affected by RNA silencing in plants (Wei et al. 2012). It might be expected, therefore, that there is an increase in mutations in the progeny of stressed plants because of the targeting of the DNA repair machinery by siRNAs. However, this possibility has not yet been tested experimentally and, at present, is hypothetical. Similarly, there is the hypothetical possibility, based on a precedent in mammalian cancer, that methylation of $\mathrm{C}$ bases accelerates the transition to Tat genomic loci that are hypermethylated in response to stress (Laird and Jaenisch 1994).

Other genetic effects could be related to the epigenetic control of transposons. The transcription of the Onsen family of copia retrotransposons, for example, was increased after extreme temperature shifts $\left(4^{\circ} \mathrm{C}\right.$ to $\left.37^{\circ} \mathrm{C}\right)$ and, consistent with the involvement of epigenetics, this effect persisted for up to seven days. This activation of Onsen results in frequent retrotranspositions in the progeny of the stressed plants if the plants are mutant for siRNA production (Ito et al. 2011) and the new inserts may disrupt the gene or direct the establishment of epigenetic marks. In either scenario, the induced epigenetic effect would have induced a genetic rearrangement leading to an altered pattern of gene expression.

A study of nutrient stress-induced heritable changes in flax may also illustrate the potential of the environment to induce DNA rearrangements that influence gene expression. Flax plants with a "plastic" genotype grew as large plants under high nutrient conditions and were small under low nutrient conditions. Many of the induced differences persisted for several generations in progeny grown under standard nutrient conditions. The inherited differences include changed height and weight, nuclear DNA content and methylation, ribosomal gene number, and seed capsule characters. These phenotypes were not grafttransmissible, but they are stable in subsequent generations (Cullis 1986).

An insertion element (LIS-1) was reconstituted reproducibly and independently in different flax lineages after the nutrient stress (Chen et al. 2005) and is likely to be one of many genomic changes associated with this heritable adaptation. Unfortunately, this phenomenon to nutrient stress is not yet fully characterized by advanced genomic techniques or next-generation sequencing. However, there are striking resonances with the genome rearrangements that occur in protozoans, mediated by a variation on the basic RNA-directed mechanism of epigenetic modification (Mochizuki et al. 2002; see Chalker et al. 2013 for more detail). It will be interesting to find out whether this flax system is a plant example of a link between epigenetics and RNA-directed genome rearrangement. 


\section{THE HERITABLE LEGACY OF INDUCED EPIGENETIC CHANGES}

Epigenetic marks show a tendency to undergo spontaneous gain or loss, as indicated by the analysis of a 30 -generation pedigree in Arabidopsis (Becker et al. 2011; Schmitz et al. 2011). It is not obvious why some loci should be prone to spontaneous epigenetic change, although the presence of overlapping and diverging transcripts may have an effect (Havecker et al. 2012). Perhaps such a configuration affects the chromatin structure so that epigenetic marks are gained and lost more easily than in other regions of the genome. Other changes may have resulted from genome interactions in hybrid ancestors of the modern varieties. In the allotetraploids of Arabidopsis, for example, there is a loss of repressive histone marks from the CCA1 and $L H Y$ circadian clock regulators, and a consequent up-regulation of 130 downstream genes that are regulated by these factors $(\mathrm{Ni}$ et al. 2009).

There is also evidence in hybrids of cultivated and wild tomato of altered production of siRNAs and, at one locus at least, a change in the methylation status at the associated DNA. In this instance, it seems likely that there is indeed an induced epigenetic change as a result of genome shock in the hybrid plant. However, the epigenetic change was not initiated until the $\mathrm{F}_{2}$ or later generations. It could be that there is a delayed onset of the epigenetic change or that it was initiated in the $\mathrm{F}_{1}$ and that its strength increased progressively over several generations (Shivaprasad et al. 2012). A priority for future research will be to find out the relative contribution of the different mechanisms to the epigenomes of wild and cultivated plants.

\section{PERSPECTIVE}

Epigenetic regulation can be considered as an additional layer in the genetic regulation of complex systems that is subject to environmental influence. However, unlike many other regulatory mechanisms, the epigenetic systems have the potential to store information over time-they are a molecular memory. This memory can be viewed as part of a "soft inheritance" system (Richards 2006). The "soft" descriptor refers to the potential for environmental influence and rapid introduction of heritable phenotypic effects; the "hard" inheritance of genetics, in contrast, is relatively insensitive to these external influences.

A striking illustration of soft inheritance is shown by genotypically identical (doubled haploid) oilseed rape lineages that were selected for either high- or low-respiration rates (Hauben et al. 2009). Four rounds of selection gave rise to lineages with heritable differences in energy use efficiencies and yield potential. It is unlikely that such differences could have arisen through genetic change in such a short time; thus, an epigenetic explanation is most likely.

There is, therefore, great potential for environmentally mediated epigenetic change to generate variation, and thus influence evolution in plants. The ease of connecting environmental and epigenetic regulation in plants is likely to be good for the cross-fertilization of ideas between the plant and animal kingdoms.

\section{REFERENCES}

* Reference is also in this collection.

Aikawa S, Kobayashi MJ, Satake A, Shimizu KK, Kudoh H. 2010. Robust control of the seasonal expression of the Arabidopsis FLC gene in a fluctuating environment. Proc Natl Acad Sci 107: 11632-11637.

Angel A, Song J, Dean C, Howard MA. 2011. A Polycomb-based switch underlying quantitative epigenetic memory. Nature 476: 105-108.

Azevedo J, Garcia D, Pontier D, Ohnesorge S, Yu A, Garcia S, Braun L, Bergdoll M, Hakimi MA, Lagrange T, et al. 2010. Argonaute quenching and global changes in Dicer homeostasis caused by a pathogenencoded GW repeat protein. Genes Dev 24: 904-915.

Baulcombe DC. 1999. Fast forward genetics based on virus-induced gene silencing. Curr Opin Plant Biol 2: 109-113.

Baulcombe D. 2004. RNA silencing in plants. Nature 431: 356-363.

Becker C, Hagmann J, Muller J, Koenig D, Stegle O, Borgwardt K, Weigel D. 2011. Spontaneous epigenetic variation in the Arabidopsis thaliana methylome. Nature 480: 245-249.

Burn JE, Bagnall DJ, Metzger JD, Dennis ES, Peacock WJ. 1993. DNA methylation, vernalization, and the initiation of flowering. Proc Natl Acad Sci 90: 287-291.

* Chalker DL, Meyer E, Mochizuki K. 2013. Epigenetics of ciliates. Cold Spring Harb Perspect Biol doi: 10.1101/cshperspect.a017764.

Chen Y, Schneeberger RG, Cullis CA. 2005. A site-specific insertion sequence in flax genotrophs induced by environment. New Phytol 167: $171-180$.

Chen H-M, Li Y-H, Wu S-H. 2007. Bioinformatic prediction and experimental validation of a microRNA-directed tandem trans-acting siRNA cascade in Arabidopsis. Proc Natl Acad Sci 104: 3318-3323.

Chen H-M, Chen L-T, Patel K, Li Y-H, Baulcombe DC, Wu S-H. 2010. 22-nucleotide RNAs trigger secondary siRNA biogenesis in plants. Proc Natl Acad Sci 107: 15269-15274.

Choi J, Hyun Y, Kang MJ, In Yun H, Yun JY, Lister C, Dean C, Amasinno RM, Noh B, Noh YS, et al. 2009. Resetting and regulation of Flowering Locus $C$ expression during Arabidopsis reproductive development. Plant J 57: 918-931.

Coustham V, Li P, Strange A, Lister C, Song J, Dean C. 2012. Quantitative modulation of Polycomb silencing underlies natural variation in vernalization. Science 337: 584-587.

Crevillén P, Dean C. 2010. Regulation of the floral repressor gene FLC: The complexity of transcription in a chromatin context. Curr Opin Plant Biol 14: 38-44.

Cullis CA. 1986. Phenotypic consequences of environmentally induced changes in plant DNA. Trends Genet 2: 307-309.

Davies WJ, Zhang J, Yang J, Dodd IC. 2010. Novel crop science to improve yield and resource use efficiency in water-limited agriculture. J Agric Sci 149: 123-131.

Deleris A, Gallego-Bartolome J, Bao J, Kasschau KD, Carrington JC, Voinnet O. 2006. Hierarchical action and inhibition of plant Dicerlike proteins in antiviral defense. Science 313: 68-71.

De Lucia F, Crevillen P, Jones AM, Greb T, Dean C. 2008. A PHD-polycomb repressive complex 2 triggers the epigenetic silencing of FLC during vernalization. Proc Natl Acad Sci 105: 16831-16836. 
Derrien B, Baumberger N, Schepetilnikov M, Viotti C, De Cillia J. 2012. Degradation of the antiviral component ARGONAUTE1 by the autophagy pathway. Proc Natl Acad Sci 109: 15942-15946.

Ding S-W, Voinnet O. 2007. Antiviral immunity directed by small RNAs. Cell 130: 413-426.

Dowen RH, Pelizzola M, Schmitz RJ, Lister R, Dowen JM, Nery JR, Dixon JE, Ecker JR. 2012. Widespread dynamic DNA methylation in response to biotic stress. Proc Natl Acad Sci 109: E2183-E2191.

Dunoyer P, Voinnet O. 2005. The complex interplay between plant viruses and host RNA-silencing pathways. Curr Opin Plant Biol 8: 415-423.

* Dunoyer P, Melnyk CW, Molnar A, Slotkin RK. 2013. Plant mobile small RNAs. Cold Spring Harb Perspect Biol 5: a017897.

Eamens A, Wang M-B, Smith NA, Waterhouse PM. 2008. RNA silencing in plants: yesterday, today, and tomorrow. Plant Physiol 147: 456-468.

Finnegan EJ, Peacock WJ, Dennis ES. 2000. DNA methylation, a key regulator of plant development and other processes. Curr Opin Genet Dev 2: 217-223.

Finnegan E, Kovac KA, Jaligot E, Sheldon CC, James Peacock W, Dennis ES. 2005. The downregulation of FLOWERING LOCUS C (FLC) expression in plants with low levels of DNA methylation and by vernalization occurs by distinct mechanisms. Plant J 44: 420-432.

Gasciolli V, Mallory AC, Bartel DP, Vaucheret H. 2005. Partially redundant functions of Arabidopsis DICER-like enzymes and a role for DCL4 in producing trans-acting siRNAs. Curr Biol 15: 1494-1500.

Gazzani S, Gendall AR, Lister C, Dean C. 2003. Analysis of the molecular basis of flowering time variation in Arabidopsis accessions. Plant Physiol 132: $1107-1114$

Gendall AR, Levy YY, Wilson A, Dean C. 2001. The VERNALIZATION 2 gene mediates the epigenetic regulation of vernalization in Arabidopsis. Cell 107: 525-535.

Geraldo N, Bäurle I, Kidou S, Hu X, Dean C. 2009. FRIGIDA delays flowering in Arabidopsis via a cotranscriptional mechanism involving direct interaction with the nuclear cap-binding complex. Plant Physiol 150: $1611-1618$.

Greb T, Mylne JS, Crevillen P, Geraldo N, An H, Gendall AR, Dean C. 2007. The PHD finger protein VRN5 functions in the epigenetic silencing of Arabidopsis FLC. Curr Biol 17: 73-78.

* Grossniklaus U, Paro R. 2014. Transcriptional silencing by Polycomb-group proteins. Cold Spring Harb Perspect Biol doi: 10.1101/ cshperspect.a019331.

Gutierrez-Marcos JF, Dickinson HG. 2012. Epigenetic reprogramming in plant reproductive lineages. Plant Cell Physiol 53: 817-823.

Hauben M, Haesendonckx B, Standaert E, Van Der Kelen K, Azmi A, Van Breusegem F, Guisez Y, Bots M, Lambert B, Laga B, et al. 2009. Energy use efficiency is characterized by an epigenetic component that can be directed. Proc Natl Acad Sci 106: 20109-20114.

Havecker ER, Wallbridge LM, Hardcastle TJ, Bush MS, Kelly KA, Dunn RM, Schwach F, Doonan JH, Baulcombe DC. 2010. The Arabidopsis RNA-directed DNA methylation argonautes functionally diverge based on their expression and interaction with target loci. Plant Cell 22: $321-334$.

Havecker ER, Wallbridge LM, Fedito P, Hardcastle TJ, Baulcombe DC. 2012. Metastable differentially methylated regions within Arabidopsis inbred populations are associated with modified expression of noncoding transcripts. PloS One 7: e45242.

He Y, Doyle MR, Amasino RM. 2004. PAF1-complex-mediated histone methylation of FLOWERING LOCUS C chromatin is required for the vernalization-responsive, winter-annual habit in Arabidopsis. Genes Dev 18: $2774-2784$.

Holeski LM, Chase-Alone R, Kelly JK. 2010. The genetics of phenotypic plasticity in plant defense: Trichome production in Mimulus guttatus. Am Nat 175: 391-400.

Hornyik C, Terzi LC, Simpson GG. 2010. The spen family protein FPA controls alternative cleavage and polyadenylation of RNA. Dev Cell 18: $203-213$.
Ito H, Gaubert H, Bucher E, Mirouze M, Vaillant I, Paszkowski J. 2011. An siRNA pathway prevents transgenerational retrotransposition in plants subjected to stress. Nature 472: 115-119.

Jiang D, Gu X, He Y. 2009. Establishment of the winter-annual growth habit via FRIGIDA-mediated histone methylation at FLOWERING LOCUS C in Arabidopsis. Plant Cell 21: 1733-1746.

Johanson U, West J, Lister C, Michaels S, Amasino R, Dean C. 2000. Molecular analysis of FRIGIDA, a major determinant of natural variation in Arabidopsis flowering time. Science 290: 344-347.

Jones L, Ratcliff F, Baulcombe DC. 2001. RNA-directed transcriptional gene silencing in plants can be inherited independently of the RNA trigger and requires Met1 for maintenance. Curr Biol 11: 747-757.

Kanazawa A, Inaba J, Shimura H, Otagaki S, Tsukahara S, Matsuzawa A, Kim BM, Goto K, Masuta C. 2011. Virus-mediated efficient induction of epigenetic modifications of endogenous genes with phenotypic changes in plants. Plant J 65: 156-168.

Kumar SV, Wigge PA. 2010. H2A.Z-containing nucleosomes mediate the thermosensory response in Arabidopsis. Cell 140: 136-147.

Laird PW, Jaenisch R. 1994. DNA methylation and cancer. Hum Mol Genet 3: 1487-1495.

Law JA, Jacobsen SE. 2010. Establishing, maintaining and modifying DNA methylation patterns in plants and animals. Nat Rev Genet 11: 204-220.

Liu F, Quesada V, Crevillén P, Bäurle I, Swiezewski S, Dean C. 2007. The Arabidopsis RNA-binding protein FCA requires a lysine-specific demethylase 1 homolog to downregulate FLC. Mol Cell 28: 398-407.

Liu F, Marquardt S, Lister C, Swiezewski S, Dean C. 2010. Targeted 3' processing of antisense transcripts triggers Arabidopsis FLC chromatin silencing. Science 327: 94-97.

Lu R, Malcuit I, Moffett P, Ruiz MT, Peart J, Wu A-J, Rathjen JP, Bendahmane A, Day L, Baulcombe D. 2003. High throughput virus-induced gene silencing implicates heat shock protein 90 in plant disease resistance. $E M B O J$ 22: 5690-5699.

Luna E, Bruce TJA, Roberts MR, Flors V, Ton J. 2012. Next-generation systemic acquired resistance. Plant Physiol 158: 844-853.

Luna E, Ton J. 2012. The epigenetic machinery controlling transgenerational systemic acquired resistance. Plant Signal Behav 7: 615-618.

Manavella PA, Koenig D, Weigel D. 2012. Plant secondary siRNA production determined by microRNA-duplex structure. Proc Natl Acad Sci 109: 2461-2466.

* Martienssen R, Moazed D. 2014. RNAi and heterochromatin assembly. Cold Spring Harb Perspect Biol doi: 10.1101/cshperspect.a019323.

Martin-Hernandez AM, Baulcombe DC. 2008. Tobacco rattle virus 16kilodalton protein encodes a suppressor of RNA silencing that allows transient viral entry in meristems. J Virol 82: 4064-4071.

Melnyk CW, Molnar A, Bassett A, Baulcombe DC. 2011. Mobile $24 \mathrm{nt}$ small RNAs direct transcriptional gene silencing in the root meristems of Arabidopsis thaliana. Curr Biol 21: 1678-1683.

Michaels SD, Amasino RM. 1999. FLOWERING LOCUS C encodes a novel MADS domain protein that acts as a repressor of flowering. Plant Cell 11: 949-956.

Mochizuki K, Fine NA, Fujisawa T, Gorovsky MA. 2002. Analysis of a piwi-related gene implicates small RNAs in genome rearrangement in Tetrahymena. Cell 110: 689-699.

Molinier J, Ries G, Zipfel C, Hohn B. 2006. Transgeneration memory of stress in plants. Nature 442: 1046-1049.

Molnar A, Melnyk CW, Bassett A, Hardcastle TJ, Dunn R, Baulcombe DC. 2010. Small silencing RNAs in plants are mobile and direct epigenetic modification in recipient cells. Science 328: 872-875.

Mylne JS, Barrett L, Tessadori F, Mesnage S, Johnson L, Bernatavichute YV, Jacobsen SE, Fransz P, Dean C. 2006. LHP1, the Arabidopsis homolog of HETEROCHROMATIN PROTEIN1, is required for epigenetic silencing of FLC. Proc Natl Acad Sci 103: 5012-5017.

Ni Z, Kim ED, Ha MS, Lackey E, Liu JX, Zhang YR, Sun QX, Chen ZJ. 2009. Altered circadian rhythms regulate growth vigour in hybrids and allopolyploids. Nature 457: 327-331. 
Oh S, Zhang H, Ludwig P, van Nocker S. 2004. A mechanism related to the yeast transcriptional regulator Paf1c is required for expression of the Arabidopsis FLC/MAF MADS box gene family. Plant Cell 16: $2940-2953$.

Otagaki S, Kawai M, Masuta C, Kanazawa A. 2011. Size and positional effects of promoter RNA segments on virus-induced RNA-directed DNA methylation and transcriptional gene silencing. Epigenetics 6: 681-691.

Park S, Oh S, Ek-Ramos J, van Nocker S. 2010. PLANT HOMOLOGOUS TO PARAFIBROMIN is a component of the PAF1 complex and assists in regulating expression of genes within H3K27ME3-enriched chromatin. Plant Physiol 153: 821-831.

Pecinka A, Dinh HQ, Baubec T, Rosa M, Lettner N, Mittelsten Scheid O. 2010. Epigenetic regulation of repetitive elements is attenuated by prolonged heat stress in Arabidopsis. Plant Cell 22: 3118-3129.

Pellegrini M, Wang G, Meyers BC, Fellowship DY. 2013. Plants regenerated from tissue culture contain stable epigenome changes in rice. eLife 2: $\mathrm{e} 00354$.

* Pikaard C, Mittelsten Scheid O. 2014. Epigenetic regulation in plants. Cold Spring Harb Perspect Biol doi: 10.1101/cshperspect.a019315.

Ptashne M. 2007. On the use of the word "epigenetic." Bioessays 17: R233-R236.

Purvis O, Gregory F. 1952. Studies in vernalisation of cereals. XII. The reversibility by high temperature of the vernalised condition in Petkus winter rye. Ann Bot 16: 1-21.

Richards EJ. 2006. Revisiting soft inheritance. Nat Rev Genet 7: 395-402.

Salgado PS, Koivunen MRL, Makeyev EV, Bamford DH, Stuart DLI, Grimes JM. 2006. The structure of an RNAi polymerase links RNA silencing and transcription. PLoS Biol 4: e434.

Schmitz RJ, Schultz MD, Lewsey MG, O'Malley RC, Urich MA, Libiger O, Schork NJ, Ecker JR. 2011. Transgenerational epigenetic instability is a source of novel methylation variants. Science 334: 369-373.

Sheldon CC, Burn JE, Perez PP, Metzger J, Edwards JA, Peacock WJ, Dennis ES. 1999. The FLF MADS box gene: A repressor of flowering in Arabidopsis regulated by vernalization and methylation. Plant Cell 11: $445-458$.

Sheldon CC, Hills MJ, Lister C, Dean C, Dennis ES, Peacock WJ. 2008. Resetting of FLOWERING LOCUS C expression after epigenetic repression by vernalization. Proc Natl Acad Sci 105: 2214-2219.

Shimura H, Pantaleo V, Ishihara T, Myojo N, Inaba J, Sueda K, Burgyán J, Masuta C. 2011. A viral satellite RNA induces yellow symptoms on tobacco by targeting a gene involved in chlorophyll biosynthesis using the RNA silencing machinery. PLoS Pathog 7: e1002021.

Shindo C, Aranzana MJ, Lister C, Baxter C, Nicholls C, Nordborg M, Dean C. 2005. Role of FRIGIDA and FLOWERING LOCUS C in determining variation in flowering time of Arabidopsis. Plant Physiol 138: $1163-1173$.

Shindo C, Lister C, Crevillen P, Nordborg M, Dean C. 2006. Variation in the epigenetic silencing of $F L C$ contributes to natural variation in Arabidopsis vernalization response. Genes Dev 20: 3079-3083.

Shivaprasad PV, Dunn RM, Santos BA, Bassett A, Baulcombe DC. 2012. Extraordinary transgressive phenotypes of hybrid tomato are influenced by epigenetics and small silencing RNAs. EMBO J 31: 257-266.

Slotkin RK, Vaughn M, Borges F, Tanurdzić M, Becker JD, Feijó JA, Martienssen RA, Tanurdzic M, Feijo JA. 2009. Epigenetic reprogramming and small RNA silencing of transposable elements in pollen. Cell 136: $461-472$.

Sung S, Amasino RM. 2004. Vernalization in Arabidopsis thaliana is mediated by the PHD finger protein VIN3. Nature 427: 159-164.

Sung S, He Y, Eshoo TW, Tamada Y, Johnson L, Nakahigashi K, Goto K, Jacobsen SE, Amasino RM. 2006a. Epigenetic maintenance of the vernalized state in Arabidopsis thaliana requires LIKE HETEROCHROMATIN PROTEIN 1. Nat Genet 38: 706-710.

Sung S, Schmitz RJ, Amasino RM. 2006b. A PHD finger protein involved in both the vernalization and photoperiod pathways in Arabidopsis. Genes Dev 20: 3244-3248.

Swiezewski S, Liu F, Magusin A, Dean C. 2009, Cold-induced silencing by long antisense transcripts of an Arabidopsis Polycomb target. Nature 462: 799-802.

Szittya G, Silhavy D, Molnár A, Havelda Z, Lovas A, Lakatos L, Bánfalvi Z, Burgyán J. 2003. Low temperature inhibits RNA silencing-mediated defence by the control of siRNA generation. EMBO J 22: 633-640.

Tamada Y, Yun JY, Woo SC, Amasino RM. 2009. ARABIDOPSIS TRITHORAX-RELATED7 is required for methylation of lysine 4 of histone $\mathrm{H} 3$ and for transcriptional activation of FLOWERING LOCUS C. Plant Cell 21: 3257-3269.

Van de Peer Y, Fawcett JA, Proost S, Sterck L, Vandepoele K. 2009. The flowering world: A tale of duplications. Trends Plant Sci 14: 680-688.

Vargason JM, Szittya G, Burgyan J, Tanaka Hall TM. 2003. Size selective recognition of siRNA by an RNA silencing suppressor. Cell 115: 799811.

Verhoeven KJF, Van Gurp TP. 2012. Transgenerational effects of stress exposure on offspring phenotypes in apomictic dandelion. PloS One 7: e38605.

Wang R, Farrona S, Vincent C, Joecker A, Schoof H, Turck F, AlonsoBlanco C, Coupland G, Albani MC. 2009. PEP1 regulates perennial flowering in Arabis alpina. Nature 459: 423-427.

Wei W, Ba Z, Gao M, Wu Y, Ma Y, Amiard S, White CI, Rendtlew Danielsen JM, Yang Y-G, Qi Y. 2012. A role for small RNAs in DNA doublestrand break repair. Cell 149: 101-112.

Werner JD, Borevitz JO, Uhlenhaut NH, Ecker JR, Chory J, Weigel D. 2005. FRIGIDA-independent variation in flowering time of natural Arabidopsis thaliana accessions. Genetics 170: 1197-1207.

Wierzbicki AT, Haag JR, Pikaard CS. 2008. Noncoding transcription by RNA polymerase Pol IVb/Pol V mediates transcriptional silencing of overlapping and adjacent genes. Cell 135: 635-648.

Wood CC, Robertson M, Tanner G, Peacock WJ, Dennis ES, Helliwell CA. 2006. The Arabidopsis thaliana vernalization response requires a polycomb-like protein complex that also includes VERNALIZATION INSENSITIVE 3. Proc Natl Acad Sci 103: 14631-14636.

Xie Z, Johansen LK, Gustafson AM, Kasschau KD, Lellis AD, Zilberman D, Jacobsen SE, Carrington JC. 2004. Genetic and functional diversification of small RNA pathways in plants. PLoS Biol 2: 642-652.

Xu L, Zhao Z, Dong A, Soubigou-Taconnat L, Renou JP, Steinmetz A, Shen WH. 2008. Di- and tri- but not monomethylation on histone H3 lysine 36 marks active transcription of genes involved in flowering time regulation and other processes in Arabidopsis thaliana. Moll Cell Biol 28: $1348-1360$.

Yu X, Michaels SD. 2010. The Arabidopsis Paf1c complex component CDC73 participates in the modification of FLOWERING LOCUS C chromatin. Plant Physiol 153: 1074-1084.

Yu A, Lepère G, Jay F, Wang J, Bapaume L, Wang Y, Abraham A-L, Penterman J, Fischer RL, Voinnet O, et al. 2013. Dynamics and biological relevance of DNA demethylation in Arabidopsis antibacterial defense. Proc Natl Acad Sci 110: 2389-2394.

Zamore PD. 2006. RNA interference: Big applause for silencing in Stockholm. Cell 127: 1083-1086.

Zhang X, Germann S, Blus BJ, Khorasanizadeh S, Gaudin V, Jacobsen S. 2007. The Arabidopsis LHP1 protein colocalizes with histone H3 Lys27 trimethylation. Nat Struct Mol Biol 14: 869-871. 


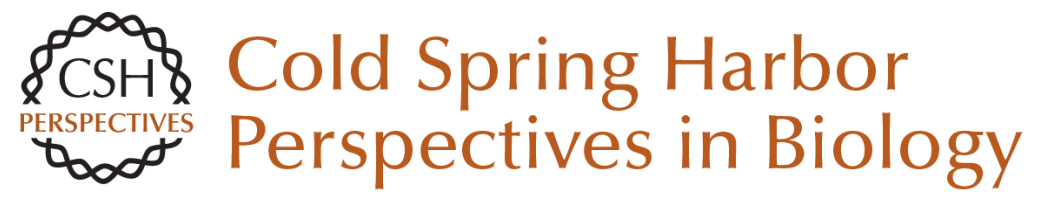

\section{Epigenetic Regulation in Plant Responses to the Environment}

David C. Baulcombe and Caroline Dean

Cold Spring Harb Perspect Biol 2014; doi: 10.1101/cshperspect.a019471

Subject Collection Epigenetics

Metabolic Signaling to Chromatin Shelley L. Berger and Paolo Sassone-Corsi

Histone and DNA Modifications as Regulators of Neuronal Development and Function Stavros Lomvardas and Tom Maniatis

Histone Modifications and Cancer James E. Audia and Robert M. Campbell

Epigenetics and Human Disease Huda Y. Zoghbi and Arthur L. Beaudet

Induced Pluripotency and Epigenetic Reprogramming Konrad Hochedlinger and Rudolf Jaenisch

Long-Range Chromatin Interactions Job Dekker and Tom Misteli

RNAi and Heterochromatin Assembly Robert Martienssen and Danesh Moazed

Dosage Compensation in Drosophila John C. Lucchesi and Mitzi I. Kuroda
Epigenetic Determinants of Cancer Stephen B. Baylin and Peter A. Jones

Maintenance of Epigenetic Information Geneviève Almouzni and Howard Cedar

A Structural Perspective on Readout of Epigenetic Histone and DNA Methylation Marks Dinshaw J. Patel

The Necessity of Chromatin: A View in

Perspective Vincenzo Pirrotta

Germline and Pluripotent Stem Cells Wolf Reik and M. Azim Surani

Comprehensive Catalog of Currently Documented Histone Modifications Yingming Zhao and Benjamin A. Garcia

Epigenetic Regulation of Chromatin States in Schizosaccharomyces pombe Robin C. Allshire and Karl Ekwall

Histone Variants and Epigenetics Steven Henikoff and M. Mitchell Smith

For additional articles in this collection, see http://cshperspectives.cshlp.org/cgi/collection/

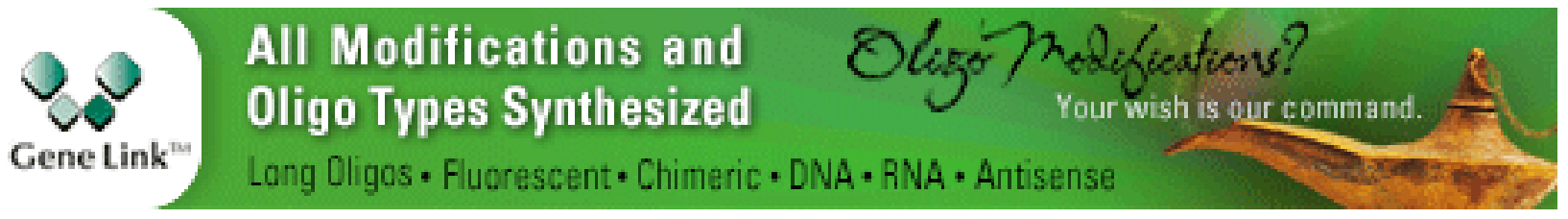

Copyright (C) 2014 Cold Spring Harbor Laboratory Press; all rights reserved 
For additional articles in this collection, see http://cshperspectives.cshlp.org/cgi/collection/

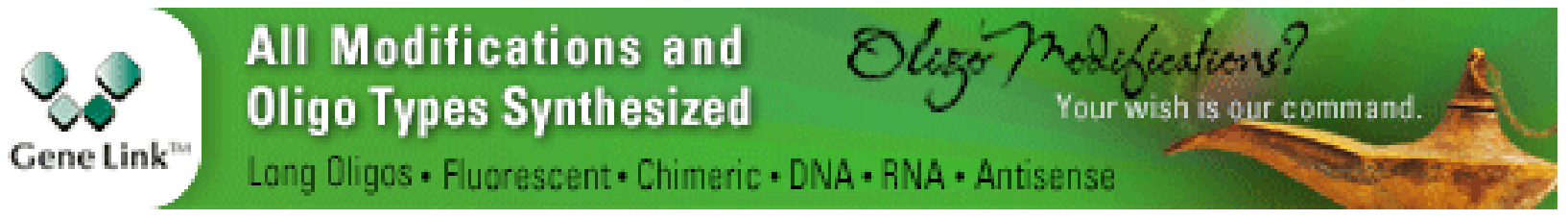

Copyright @ 2014 Cold Spring Harbor Laboratory Press; all rights reserved 